\title{
Effects of ocean mesoscale eddies on atmosphere-sea ice-ocean interactions off Adélie Land, East Antarctica
}

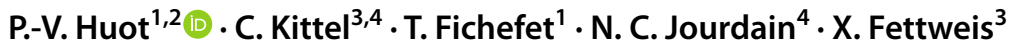

Received: 16 September 2021 / Accepted: 16 December 2021 / Published online: 22 January 2022

(c) The Author(s) 2022

\begin{abstract}
Heat and momentum exchanges at the Southern Ocean surface are crucial for the Earth's Climate, but the importance of the small-scale spatial variability of these surface fluxes is poorly understood. Here, we explore how small-scale heterogeneities of the surface conditions due in particular to ocean eddies affect the atmosphere-sea ice-ocean interactions off Adélie Land, in East Antarctica. To this end, we use a high-resolution regional atmosphere-sea ice-ocean coupled model based on the NEMO-LIM and MAR models. We explore how the atmosphere responds to small-scale heterogeneity of the ocean or sea ice surface conditions, how eddies affect the sea ice and atmosphere, and how the eddy-driven surface fluxes impact the heat, freshwater, and momentum budget of the ocean. The atmosphere is found to be more sensitive to small-scale surface temperature gradients above the ice-covered than above the ice-free ocean. Sea ice concentration is found to be weaker above anticyclonic than cyclonic eddies due to increased sea ice melting or freezing $(0.8 \mathrm{~cm} /$ day $)$ partly compensated by sea ice convergence or divergence. The imprint of ice-free eddies on the atmosphere is weak, but in the presence of sea ice, air warming $\left(+0.3{ }^{\circ} \mathrm{C}\right)$ and wind intensification $(+0.1 \mathrm{~m} / \mathrm{s})$ are found above anticyclonic eddies, while cyclonic eddies have the opposite effects. Removing the interactions of eddies with the sea ice or atmosphere does not affect the total sea ice volume, but increases the ocean kinetic energy by $8 \%$ and weakens northward advection of sea ice, leading to a $15 \%$ decrease in freshwater flux north of $62.5^{\circ} \mathrm{S}$ and weaker ocean restratification.
\end{abstract}

Keywords Southern Ocean $\cdot$ Sea ice $\cdot$ Mesoscale $\cdot$ Atmosphere-sea ice-ocean interactions $\cdot$ Regional Coupled Model

\section{Introduction}

The exchanges of heat, freshwater, and momentum at the air-sea interface are primordial drivers of the ocean circulation and especially, of the Southern Ocean circulation. The Southern Ocean is a central component of the Earth's climate: it contributes to isolate Antarctica from meridional heat transport (Martinson 2012) and hosts exchanges

P.-V. Huot

pierre-vincent.huot@uclouvain.be

1 Earth and Life Institute, George Lemaitre Centre for Earth and Climate Research, UCLouvain, Louvain-la-Neuve, Belgium

2 Present Address: Department of Earth and Environmental Sciences, KU Leuven, Leuven, Belgium

3 Laboratory of Climatology, Department of Geography, University of Liège, Liège, Belgium

4 Present Address: Universitée Grenoble Alpes, CNRS/IRD/G-INP, IGE, Grenoble, France between the surface and the deep ocean thanks to winddriven upwelling and winter deep convection (Orsi et al. 1999). The Southern Ocean is also closely tied to the Antarctic Ice Sheet: ice-shelf basal melt was found to be the main cause of Antarctic ice mass loss during the past decades (Rignot et al. 2019). Understanding the Earth's climate requires to comprehend what drives the evolution of the Southern Ocean. The Antarctic Circumpolar Current (ACC) is suggested to be forced by surface momentum (Allison et al. 2010) and buoyancy fluxes (Hogg 2010). Coupled with the ACC, the Southern Ocean hosts a meridional thermohaline circulation which is driven by surface heat and freshwater fluxes (Walin 1982; Abernathey et al. 2016) and by the wind curl (Marshall and Radko 2003). The wind curl above the Southern Ocean also drives upwelling which closes the global meridional overturning circulation (Marshall and Speer 2012). Hence, it is indubitable that the interactions between the ocean and the atmosphere or the sea ice play a substantial role in the Southern Ocean dynamics. But the understanding of the processes affecting the atmosphere-sea 
ice-ocean interactions in the Southern Ocean remains incomplete. For instance, the role of processes taking place at small scales (below $100 \mathrm{~km}$ ) such as ocean mesoscale eddies is mostly unknown due to the lack of high-resolution observations and to the cost of high-resolution models.

Ocean mesoscale eddies are swirling circulation patterns with scales ranging from 10 to $100 \mathrm{~km}$ observed almost all around the world with the exception of the equatorial oceans (Faghmous et al. 2015). At the mesoscale, the flows are still strongly affected by the Earth's rotation, which is not the case at a smaller spatial scale called the submesoscale (McWilliams 2016). Mesoscale eddies are particularly active in the energetic currents such as Western Boundary Currents or the ACC. They play an important role in the ocean dynamics as they represent most of the ocean kinetic energy (Ferrari and Wunsch 2010) and potentially contribute to the transport and mixing of temperature, salinity, or carbon (Moreau et al. 2017).

Eddies can also modulate the interactions between the ocean and the atmosphere. Indeed, eddies are often associated with anomalies of sea surface temperature, salinity, and ocean currents, which can affect the turbulent fluxes at the air-sea interface (Villas Bôas et al. 2015). Their effects on air-sea interactions have been extensively studied in the past two decades. It appears that, at small scales, the sea surface temperature variability can drive the variability of air-sea heat fluxes. For instance O'Neill et al. (2005), observed a linear relationship between surface temperature gradients and wind stress curl over the Aghulas Current. This relationship was confirmed by modelling studies (Song et al. 2009) and other observations (Chelton et al. 2007; Chelton and Xie 2010). The underlying mechanisms, described in Small et al. (2008), involve a modification of the near-surface atmosphere stability, vertical momentum transfer, and surface pressure in response to air temperature changes. Eddies also affect air-sea momentum fluxes via their imprint on surface currents. The friction of ocean eddies on the atmosphere generates a wind stress curl (Renault et al. 2017), reducing the eddy kinetic energy and lifetime (Renault et al. 2016), and affecting large-scale currents (Renault et al. 2016). Eddy-induced stress curl also generates small-scale Ekman pumping (Gaube et al. 2015). The modulation of air-sea fluxes by eddies however seems to be variable in space and time. Small et al. (2019) showed that the drivers of the air-sea fluxes' small-scale variability vary from one region to another

In the Southern Ocean, Frenger et al. (2013) and Chelton (2013) observed the imprint of eddies on wind speeds, cloud cover, and precipitation. Eddies also influence the mixedlayer depth, potentially affecting air-sea interactions (Hausmann et al. 2017). Winds can also affect eddies in return: Du Plessis et al. (2019) showed that winds could dampen the submesoscale activity of the ocean. The impact of eddies on air-sea momentum fluxes was found to impact the ACC energy budget and stratification (Song et al. 2020). Through this mechanism, eddies were suggested to drive Southern Ocean multi-decadal variability (Le Bars et al. 2016). Though it is clear that eddies influence air-sea exchanges, it is unclear whether these processes are at play in the ice-covered Southern Ocean. High-latitude eddies are often smaller (Chelton et al. 1998; LaCasce and Groeskamp 2020) than elsewhere in the ocean, limiting the possibility for the atmosphere to respond to their presence. Average winds over the Southern Ocean are particularly strong, with very frequent storms, which could reduce the relative importance of ocean currents with respect to wind velocity compared to other eddy-prone regions. The low sea ice temperature may lead to the development of temperature inversions making the low-level atmosphere very stable, inhibiting the atmosphere sensitivity to surface conditions. Besides, thermal contrast between sea ice and leads or polynyas may induce mesoscale convective features (Gryschka et al. 2008). Finally, thick sea ice insulates the ocean from the atmosphere and could shut down mesoscale air-sea interactions during winter. Whether eddies impact air-sea interactions to a significant extent over the Southern Ocean regions remains an open question.

The imprint of eddies on the atmosphere can arise from their imprint on sea ice. Recent observations suggest that eddies affect the sea ice concentration and drift. By detecting the imprint of eddies on sea ice concentration, Kozlov et al. (2019) described the eddy activity in the Arctic. Cassianides et al. (2021) proposed a method to detect eddies beneath sea ice via their imprint on the sea ice vorticity. Eddy-like swirls can also be found in the sea ice [see Fig. 1 of Manucharyan and Thompson (2017)]. The interactions of eddies with sea ice have already been simulated in several models. Manucharyan and Thompson (2017) suggested that eddies and sea ice interact in the development of the Marginal Ice Zone (MIZ). They showed that eddies spontaneously appear in the MIZ where they affect sea ice advection and oceanice heat fluxes. Besides, the curl of eddies currents leads to sea ice divergence or convergence, affecting the air-sea and ocean-ice heat exchanges. Similar to the friction of eddies on the atmosphere (Renault et al. 2016), eddies also rub on the sea ice, which drives Ekman pumping or eddy-ice pumping (EIP) in the ocean. This process is described in Gupta et al. (2020), who showed that EIP reduced sea ice thickness by $10 \%$ and mixed layer depth by $60 \%$ due to increased sea ice melt in an idealized Southern Ocean simulation. Sea ice can also affect the eddy activity. Meneghello et al. (2020) showed that the friction of eddies on the Arctic sea ice was one of the reasons for the decay of ocean mesoscale activity in winter. Horvat et al. (2016) showed that lateral density gradients linked with sea ice melting at the edges of ice floes drive submesoscale circulation. As mesoscale eddies influence sea ice, they could as well affect the air-sea interactions 
and the atmosphere in ice-covered regions. Observations of small-scale atmosphere-sea ice-ocean interactions are however too scarce to evaluate the role of eddies.

With the present study, our goal is to explore how mesoscale eddies influence air-sea interactions in the presence of sea ice. We use a regional high-resolution ocean-sea ice-atmosphere model to analyze the influence of mesoscale eddies on sea ice, atmosphere, and air-sea-ice exchanges from the scale of the eddies to the regional scale. To do so, we have developed a high-resolution regional coupled model of the ocean, sea ice, and atmosphere based on the NEMO-LIM (ocean and sea ice) and MAR (atmosphere) models (Sect. 2). This model enables the study of atmosphere-sea ice-ocean interactions at scales where observations are missing and coupled models are rarely used. Due to the high cost of such a high-resolution coupled model, we limit our study to the Adélie Land sector, East Antarctica. Our regional coupled model is presented in Sect. 2. We then analyze to what extent individual eddies affect the overlying sea ice and atmosphere properties (Sect. 3) and we describe the overall effect in the entire simulated region (Sect. 4). The results are discussed in Sect. 5, followed by our conclusions.

\section{The model, experimental design, and analysis strategy}

\subsection{The NEMO ocean-sea ice model}

The ocean-sea ice model is adapted from the one used in Huot et al. (2021a) and Huot et al. (2021b). It is a regional configuration of the NEMOv3.6 platform (Nucleus for European Modelling of the Ocean, Madec (2016)), including the sea ice model LIM3 (Louvain-la-Neuve sea Ice Model). The ocean domain extends from $70^{\circ} \mathrm{S}$ to $59^{\circ} \mathrm{S}$ and from $129^{\circ} \mathrm{E}$ to $151^{\circ} \mathrm{E}$. The grid is derived from the eORCA1 global tripolar grid which was refined to a resolution of $1 / 24^{\circ}$. The grid spacing ranges from 1.8 to 2.3 $\mathrm{km}$, which is enough to resolve eddies away from the continental shelves (Hallberg 2013). The vertical discretization consists of 75 levels of increasing thickness from top to bottom (from 1 to $200 \mathrm{~m}$ ). The vertical mixing is treated via a TKE scheme (Bougeault and Lacarrere 1989; Gaspar et al. 1990). Convection is parameterized by enhanced vertical mixing in case of unstable stratification (Lazar et al. 1999). LIM3 is a dynamic-thermodynamic model described in Vancoppenolle et al. (2009) and Rousset et al. (2015). We make use of a subgrid-scale distribution of sea ice thicknesses with 5 categories. We have increased the ocean-ice drag coefficient to $6.8 \times 10^{-3}$ (instead of $5 \times 10^{-3}$ in Huot et al. (2021a)) to adjust to the stronger wind stress provided by MAR compared to the one calculated with the bulk CORE formula (Large and Yeager
2004) in forced mode. The parameterization of landfast sea ice (Van Achter et al. 2021; Huot et al. 2021b) was modified: sea ice experiences a bottom stress where a grounded iceberg is present, instead of treating icebergs as land points. The bottom stress is set to $\tau_{l f s}=a_{i} \tau_{i c b}$ (with $a_{i}$ the sea ice concentration and $\tau_{i c b}$ a constant stress of $10 \mathrm{~N} / \mathrm{m}^{2}$ ). The two methods produce similar results, but the one used here does not require adapting the land-sea mask. The ocean-sea ice model is forced at its lateral boundaries by the PSY4V3R1 $1 / 12^{\circ}$ global reanalysis as in Huot et al. (2021b). Tides are applied at the lateral boundaries using the FES2012 dataset (Carrère et al. 2012), as in Maraldi et al. (2013) and Jourdain et al. (2019).

\subsection{The atmospheric model MAR}

MAR (Modèle Atmosphérique Regional) is a hydrostatic polar-oriented model originally developed by Gallée and Schayes (1994). This model has often been used to study the climate over the Antarctic Ice Sheet (e.g., Amory et al. (2015); Kittel et al. (2018); Agosta et al. (2019); DonatMagnin et al. (2020)). We refer to Kittel et al. (2021) for a description and evaluation of MAR all over Antarctica. The MAR configuration used in this study was adapted from the one utilized in Huot et al. (2021b), and the MAR model was updated to version 3.11. The model uses the $E-\epsilon$ scheme of Duynkerke (1988) for the subgrid-scale vertical fluxes. MAR is coupled to the surface model SISVAT from De Ridder and Gallée (1998) (part of which is based on a former version of the CROCUS model for snow-covered surfaces (Brun et al. 1992)). Each grid cell of MAR in our configuration is either a land cell, possibly including a nunatak fraction, or an ocean cell, possibly including a fraction of sea ice. Sea sprays enhance evaporation acting as a moisture source over the ocean and decreasing the air potential temperature (Andreas and Decosmo 2002). The atmospheric model is forced at its lateral boundaries and nudged in the top troposphere by 6-hourly outputs of ERA5 (Hersbach et al. 2020). The atmospheric state obtained from ERA5 is imposed at the MAR boundaries with a 7-pixel relaxation zone (see Marbaix et al. (2003) for details about the boundary treatment in MAR). The synoptic variability is thus mostly driven by the lateral forcing, ensuring the realism of the coupled model simulations. MAR evolves freely within the inner domain (outside the 7-pixel relaxation zone). The horizontal resolution is set to $5 \mathrm{~km}$ (same grid as the AM5 simulation of Huot et al. (2021b)). The vertical discretization consists of 24 sigma levels, with the first level at approximately $2 \mathrm{~m}$. The atmospheric domain is larger than the one covered by the ocean model and MAR takes its surface conditions from the OSTIA reanalysis (Donlon et al. 2012) outside of the 
common area. A relaxation zone of 5 grid points is used between the coupled and uncoupled surfaces.

\subsection{NEMO-MAR coupling}

We have revised the coupling interface originally developed by Jourdain et al. (2011), by updating all model components, including the OASIS3-MCT3 coupler (Craig et al. 2017), by coupling at a higher frequency, and by revisiting some of the flux formulations. MAR computes the fluxes for NEMO-LIM, and NEMO-LIM sends its surface conditions to MAR. The coupling time step is $600 \mathrm{~s}$ (equal to 4 oceanic time steps and 30 atmospheric time steps). Every coupling time step, NEMO-LIM sends its 600 -s averaged sea surface temperature, sea surface velocities, sea ice concentration, sea ice and snow thicknesses, sea ice albedo, sea ice surface temperature, and sea ice velocities. Sea ice albedo is a function of ice surface temperature, ice, and snow depth (Shine and HendersonSellers 1985). The ocean albedo is recomputed in MAR and is a function of the zenithal angle and cloud cover. MAR sends net shortwave radiation, the non-solar heat flux (sum of net longwave, latent and sensible heat fluxes), and the turbulent momentum flux separately for the sea ice and the ocean to NEMO-LIM. In addition, MAR sends rainfall and snowfall, ice sublimation, and total evaporation. MAR also sends the non-solar heat flux sensitivity to surface temperature. The latter (computed as in Jourdain et al. (2011)) is used to adjust the fluxes to the actual sea ice temperature in NEMO-LIM to avoid large-amplitude noise in the sea ice temperature. All exchanged fields are interpolated bi-linearly in the longitude-latitude space between the two grids (this method is non-conservative, but avoid the apparition of unphysical fluxes). Though the sea ice component LIM has a subgrid-scale ice thickness distribution, it is not the case for the atmosphere. NEMOLIM, therefore, sends the fraction-weighted average of the distributed variables (ice and snow thicknesses, ice temperature). The same air-ice fluxes are then applied to each sea ice category.

As in Renault et al. (2016), we use relative winds for the wind stress computation over ocean or sea ice. The relative zonal wind speed $U_{r e l}$ is defined as: $U_{\text {rel }}=\left(U_{10 m}-U_{o c e}\right)(1-a)+\left(U_{10 m}-U_{i c e}\right) a$, with $U_{10 m}$ the $10 \mathrm{~m}$ zonal wind speed component, $U_{\text {oce }}$ the surface zonal ocean current speed, $U_{i c e}$ the zonal sea ice speed and $a$ the sea ice concentration, and similarly in the meridional direction. The surface roughness length used for the air-sea or air-ice fluxes is computed as: $z 0=z 0_{o c e}(1-a)+z 0_{i c e} a$, with $z 0_{o c e}$ and $z 0_{i c e}$ the ocean and sea ice surface roughness lengths, respectively. $z 0 m_{o c e}$, the ocean roughness length for momentum, is a function of the local wind speed after Wang (2001): $z 0 m_{\text {oce }}=0.016 \frac{(U *)^{2}}{g}+0.11 \frac{v}{U *}$, with $U *$ the friction velocity, $v$ the air kinematic viscosity $\left(1.35 \times 10^{-5} \mathrm{~m}^{2} / \mathrm{s}\right)$ and $g$ the gravitational acceleration. The roughness lengths for the sea ice latent, sensible, and momentum fluxes are constant and set to $1 \times 10^{-3} \mathrm{~m}$ as in Cassano et al. (2001) and Bromwich et al. (2001).

\subsection{Experimental design: REF and SMOOTH experiments}

The reference (REF) simulation starts on the 1st of January 2011 and ends on the 31st of December 2013, using the outputs of a stand-alone ocean simulation forced by MAR outputs as an initial state (OM5 in Huot et al. (2021b)). The first year serves as a model spin-up and is discarded from the analyses. A comparison of the mean state of the ocean with the WOA18 climatology (Zweng et al. 2018; Locarnini et al. 2018) and atmosphere with the ERA5 reanalysis (Hersbach et al. 2020) is proposed in the supplementary material. In $\mathrm{REF}$, the sea ice and the atmosphere feel the presence of the oceanic mesoscale activity which is at least partly resolved north of the continental shelf given that the effective ocean model resolution is generally estimated as 2 to 10 times the grid resolution i.e. 4 to $20 \mathrm{~km}$ in our configuration (Hallberg 2013; Soufflet et al. 2016). In comparison, LaCasce and Groeskamp (2020) estimated the 1st Rossby radius to be comprised between 10 and $20 \mathrm{~km}$ at the high latitudes of the Southern Ocean. Hence, our model should be able to resolve most of the mesoscale eddies. In addition, the $5 \mathrm{~km}$ horizontal resolution of the atmospheric model should be enough to capture the surface signature of eddies with such spatial scales.

The time series of the sea ice area simulated in REF is compared to the observed sea ice area in Fig. 1. The REF simulation offers a satisfying representation of the sea ice area (Fig. 1) when compared to the OSI-450 dataset (Lavergne et al. 2019). REF underestimates the sea ice

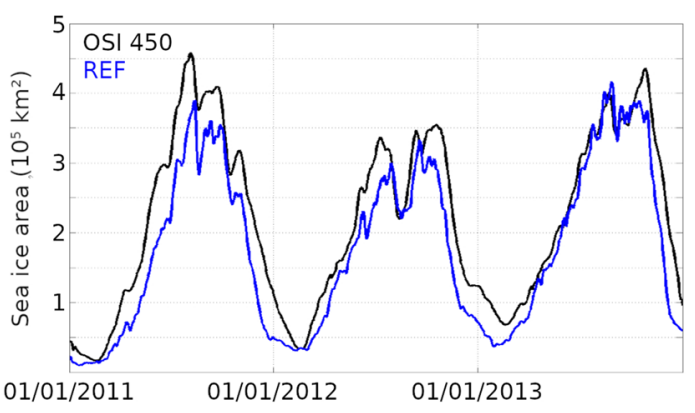

Fig. 1 Time series of sea ice area integrated over the Adélie Land sector simulated in REF and derived from the observations OSI-450 (OSI SAF Global Sea Ice Concentration Climate Data Record) 
extent by $15 \%$ in the winters of 2011 (considered as a spinup year hereafter) and 2012 while doing a better job in 2013. This negative bias may lead to an underestimation of the imprint of eddies on the sea ice pack as the eddy activity increases northwards.

The eddy kinetic energy simulated in REF and estimated from the AVISO sea level anomaly dataset are illustrated in Fig. 2. The spatial and temporal resolutions of the modeled $\left(1 / 24^{\circ}\right.$ and daily) and observed SLA (function of track density, Ballarotta et al. (2019)) are too different to permit direct comparison and some adaptation is needed to compare observations and model on an even ground (as was for instance done in Amores et al. (2018)). Here, we have reconstructed the SLA of AVISO from the along-track SLA and using the interpolation algorithm developed by Garcia (2010) and applied to geophysical datasets in Wang et al. (2012). The reconstructed SLA compares well with the AVISO interpolated field, with an averaged root mean squared error of $0.69 \mathrm{~cm}$. The same methodology is applied to the modeled field: "along-track" SLA are obtained using the real tracks of the altimeter used in AVISO, and the SLA is interpolated. Before the interpolation, we have masked the locations with an observed sea ice concentration (in the OSI450 dataset) higher than $0 \%$. The model overestimates the ocean EKE in the northwestern part of the domain (where it can be four times higher than the one estimated from AVISO) but shows reasonable values of EKE in the eastern part. The simulated EKE is however similar to that simulated by Stewart et al. (2018).

To test the effects of the ocean eddies on the atmosphere-sea ice-ocean interactions, we perform a second experiment named SMOOTH. SMOOTH starts on the 1st of January 2012, using a snapshot of the ocean, sea ice and atmosphere states from REF as initial conditions. In SMOOTH, we remove the modulation of atmosphere-sea ice-ocean heat and momentum fluxes by ocean eddies. To do so, we smooth the oceanic fields before their use in the sea ice model and before their exchange with the atmosphere model. The filter 'F' (inspired from Renault et al. (2019)) is a 2D Gaussian with a standard deviation of $40 \mathrm{~km}$. It is applied online to the sea surface temperature (SST), salinity (SSS), and meridional and zonal currents (SSU and SSV). We mirrored the oceanic fields across the lateral limits to avoid nonphysical boundary effects. We also masked land points and adapted the filter weights in the neighborhood of coastlines. The filter width (i.e., the distance after which the weights are set to zero) is set to 6 times the standard deviation of the Gaussian. In this experiment, the atmosphere and the sea ice do not feel the small-scale heterogeneity of ocean surface conditions. Note that the sea ice fields are not filtered before the exchange with the atmosphere. The same filter is used offline to isolate the mesoscale variability of a given field. We decompose a field $\mathrm{X}$ into its mesoscale part $\mathrm{X}_{\text {meso }}$ and large-scale part $\mathrm{X}_{\text {large }}$ such as $\mathrm{X}=\mathrm{X}_{\text {meso }}+\mathrm{X}_{\text {large }}$. $\mathrm{X}_{\text {large }}$ is obtained by filtering $\mathrm{X}$ by the Gaussian filter ' $F$ ' described above.

The effects of smoothing are illustrated by the snapshots of sea ice concentration and sea surface temperature in Fig. 3. The imprint of mesoscale activity is manifest on the SST of REF, with circular or swirling warm and cold anomalies. The SST of SMOOTH is exempt from these eddies and filaments (note that the eddies of both simulations are not in phase). As explained before, the sea ice fields are not smoothed in SMOOTH. The ice pack presents small-scale heterogeneity due for instance to the opening of leads and polynyas in both simulations. Yet, the ice edge has a distinct shape between both simulations: between $64^{\circ} \mathrm{S}$ and $62^{\circ} \mathrm{S}$, the eddies are deforming the ice pack. Swirling shapes in the sea ice concentration are found in REF but not in SMOOTH. This study aims to understand the mechanisms at play and their implications for the exchanges with the atmosphere. The ocean kinetic energy and SST power spectra before and after filtering (Fig. 4) show how different wavelengths are filtered. The filter effectively reduces the variability of the SST for length scales lower than $150 \mathrm{~km}$.
Fig. 2 Eddy kinetic energy obtained from geostrophic currents simulated in REF (a) and estimated from AVISO (b), averaged over 2011 and 2012
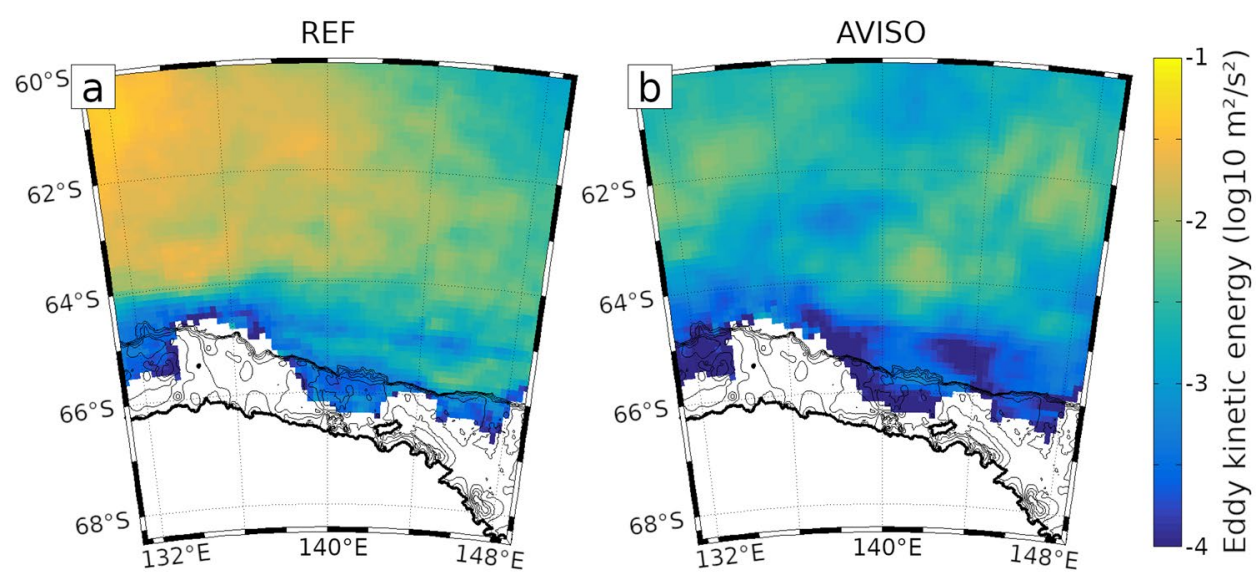

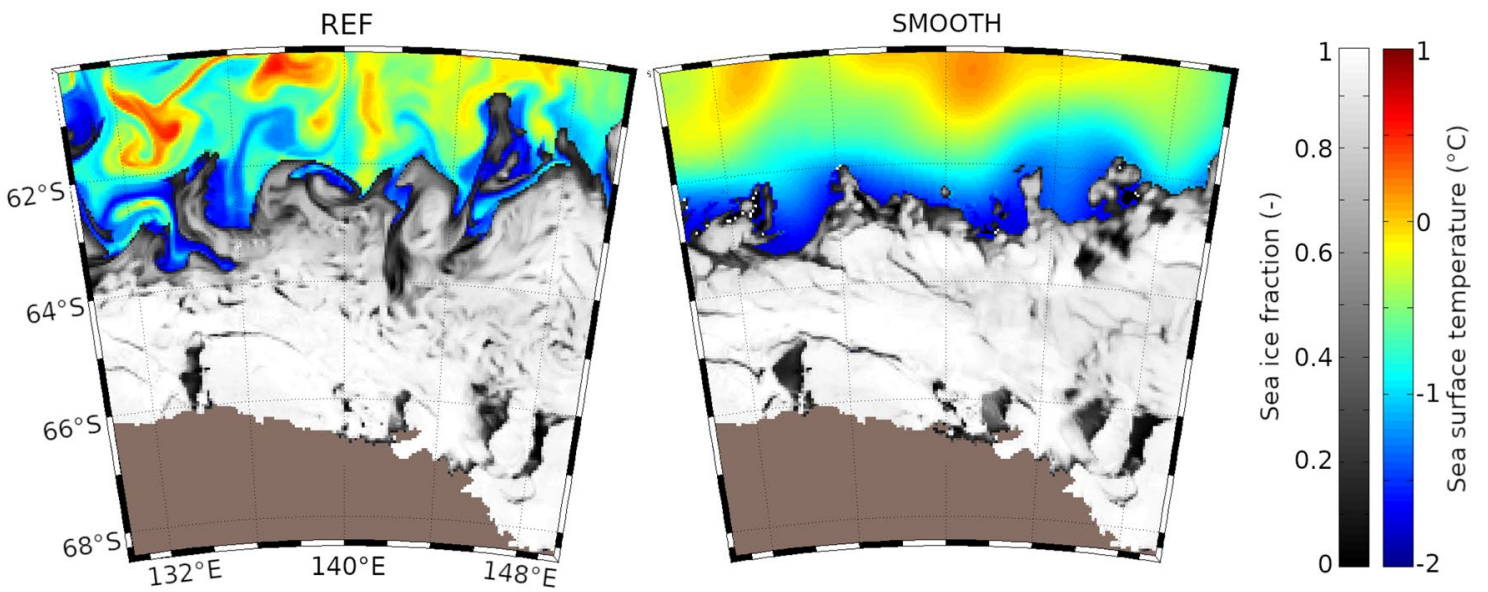

Fig. 3 Snapshots of sea ice concentration (black and white shading) and SST (red-green-blue shading) seen by MAR in REF (left) and SMOOTH (right) on 27th Aug. 2013

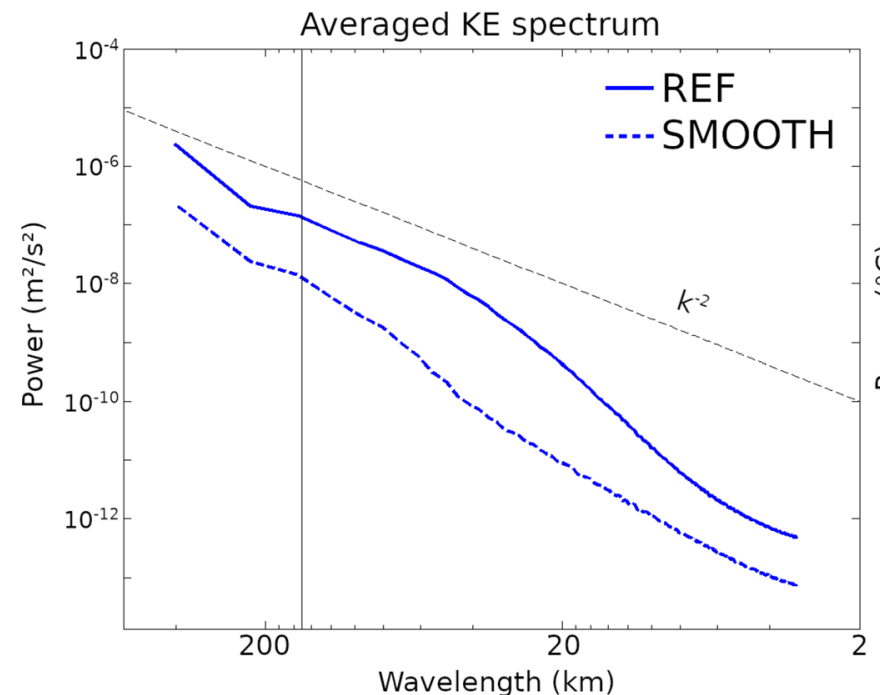

Fig. 4 Radially averaged power spectra of the ocean kinetic energy (left) and SST (right) simulated in REF and obtained after smoothing the oceanic fields of SMOOTH over the period 2012-2013. The SST is the one seen by MAR and has a resolution of $5 \mathrm{~km}$, while the ocean

Caution must be exercised when analyzing the results from the SMOOTH experiment. As described above, the filter dampens the imprint of small-scale processes on the sea surface. This includes the effects of the eddies but also the imprint of other processes (such as heterogeneous surface fluxes). Filtering the surface fields thus also dampens the small-scale feedbacks between surface fluxes and the ocean. In other words, while the ocean is free to adjust to surface fluxes, the sea ice and atmosphere see a diluted response due to the spatial filtering. This can have the effect of inhibiting the small-scale atmosphere-sea ice-ocean interactions which are not associated with ocean

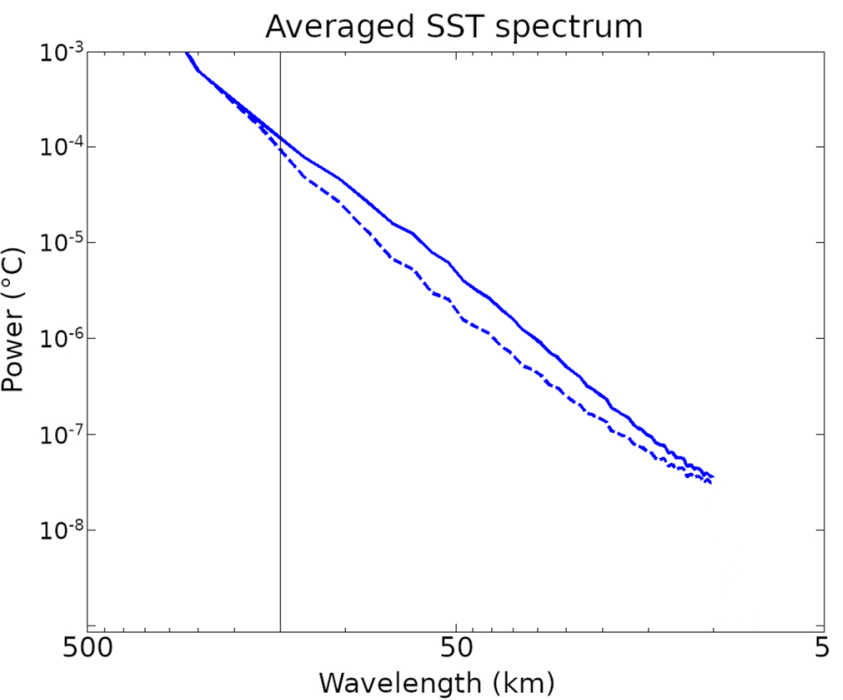

kinetic energy was recomputed offline and has a resolution of $\sim 2 \mathrm{~km}$. The dashed black line indicates the $\mathrm{k}^{-2}$ slope, and the vertical black line a wavelength of $150 \mathrm{~km}$

mesoscale activity. We carried out another experiment where the filter is applied to surface currents only (not to SST or SSS). This did not impact the results presented here (not shown). Therefore, we can confidently attribute the effects of the filtering described hereafter to the mesoscale dynamical structures (eddies, meanders).

\subsection{Eddy tracking and compositing}

As we are particularly interested in understanding the mechanisms of atmosphere-sea ice-ocean interactions induced by mesoscale ocean eddies, it is important to analyze the 
simulations at the scale of those eddies. To do so, we produced a series of sea surface and atmosphere composites above eddies. Several methods have been developed to track oceanic mesoscale eddies either based on sea-level anomalies (Chelton 2013; Frenger et al. 2013) or on flow properties (Williams et al. 2011; Haller 2016). Here, we use a method which tracks eddies using sea-level anomalies, as was for instance done in Frenger et al. (2013), Hausmann et al. (2017), or Gupta et al. (2020). The eddy tracking algorithm used here was developed by Faghmous et al. (2015). It was originally developed for remotely sensed data but can be applied to outputs from numerical models as well. The algorithm localize local extremum of SLA within squares of $9 \times$ 9 pixels. Then, it finds the largest closed contour of SLA that contains a single SLA extremum. The eddy consists of all the pixels enclosed within the largest SLA contour. Closed contours of SLA with an area lower than 300 grid points (a circle with a radius of approximately 10 grid points in our configuration) are discarded. Eddies with an SLA anomaly lower than $3 \mathrm{~cm}$ were also discarded. Note that one eddy can be detected several days in a row. The daily sea surface, sea ice, and atmospheric conditions within 3 eddy radius from the eddy center were gathered and averaged to produce composite images. These composites represent the mean state of the ocean, atmosphere, or sea ice in the eddies referenced frame. Before averaging, the eddies were scaled according to their individual eddy radius. Additionally, atmospheric fields were rotated to be aligned with the local wind direction (as in Frenger et al. (2013)) averaged over one eddy radius from the eddy center. For each variable, we make separate composites for cyclonic and anticyclonic eddies.

\section{Atmosphere-sea ice-ocean interactions at the mesoscale}

In this section, we investigate how eddies affect air-sea interactions at small scales and the mesoscale variability of the sea ice, atmosphere, and ocean. First, the response of the small-scale wind to the mesoscale surface temperature variability is assessed. Then, we describe the imprint of individual eddies on the sea ice, atmosphere, and ocean.

\subsection{Small-scale atmosphere-sea ice-ocean coupling}

In this section, we analyze how the atmosphere responds to mesoscale anomalies of surface conditions (i.e. not only eddies but all mesoscale heterogeneities).

We first focus on the thermal feedback, i.e. the anomaly of wind or stress divergence across surface temperature gradients and of wind or stress curl along surface temperature gradients (O'Neill et al. 2005; Chelton and Xie
2010). As discussed earlier, a positive surface temperature anomaly leads to wind intensification. Thus, a downwind surface temperature gradient yields a downwind wind intensification (divergence). Similarly, a crosswind surface temperature gradient leads to a crosswind wind intensification (curl). Details about the mechanisms can be found in Chelton and Xie (2010). We compute the relationships between the surface temperature (ST) gradient and wind curl or divergence using the outputs of REF. For the icecovered cells, we use the cell-averaged surface temperature of the ocean and sea ice instead of the SST. We compute the surface temperature downwind and crosswind gradients as in O'Neill et al. (2005). The downwind ST gradient is defined as: $\overrightarrow{\nabla_{d o w n}} S T=\vec{\nabla} S T \cdot \vec{k}$ and the crosswind gradient as: $\overrightarrow{\nabla_{\text {cross }}} S T=\vec{\nabla} S T \times \vec{k}$ with $\vec{k}$ a unit vector in the wind direction and $S T$ the surface temperature. We extract the mesoscale anomalies of these fields and of the wind $\operatorname{curl}(\vec{\nabla} \times \vec{U}$, with $\vec{U}$ the $10 \mathrm{~m}$ wind) and divergence $(\vec{\nabla} \cdot \vec{U})$ using the filter $\mathrm{F}$ described in Sect. 2.4. The ST gradients simulated over the whole sector in 2012 and 2013 are then gathered into bins (with a width of $1 \times 10^{-6}{ }^{\circ} \mathrm{C} / \mathrm{m}$ ). The wind curl or divergence simulated for each ST gradient range are averaged. We then derive the relationship between the binned ST gradients and bin-averaged wind conditions. A relationship is calculated for ice-free $(S I C=0)$ and one for ice-covered $($ SIC $>0.05)$ cases.

The resulting binned scatterplots are displayed in Fig. 5a, b (and their associated spread in Supplementary Fig. B.3 and B.4). For the ice-free ocean, there is a positive relationship between the crosswind gradient of surface temperature and the wind curl. A positive relationship is also found between the downwind surface temperature gradient and the wind curl. These positive relationships are in agreement with previous work (Chelton and Xie 2010; Song et al. 2009). The relationships are also positive for the ice-covered ocean, but the coupling is stronger. The slopes of the crosswind ST — wind curl relationship and of the downwind ST — wind divergence relationship are indeed increased by a factor of 2 in the presence of sea ice. This stronger response above sea ice can arise from a stronger sensitivity of the cold and stable atmospheric boundary layer to surface temperature gradients, but also from the higher heat transfer coefficient over the sea ice than over the ocean in our model.

Then we focus on the so-called current feedback (Renault et al. 2016), which depends on the relative velocity of wind and ocean currents. This feedback induces wind stress curl over ocean vorticity, which tends to extract vorticity from the ocean and therefore to weaken ocean eddies. Renault et al. (2016) defined the dynamical coupling as the relationship between the surface currents vorticity and the wind or surface stress curl. Here, we use the relative vorticity of geostrophic currents (hereafter geostrophic vorticity), i.e. the curl of the geostrophic currents derived from the simulated 


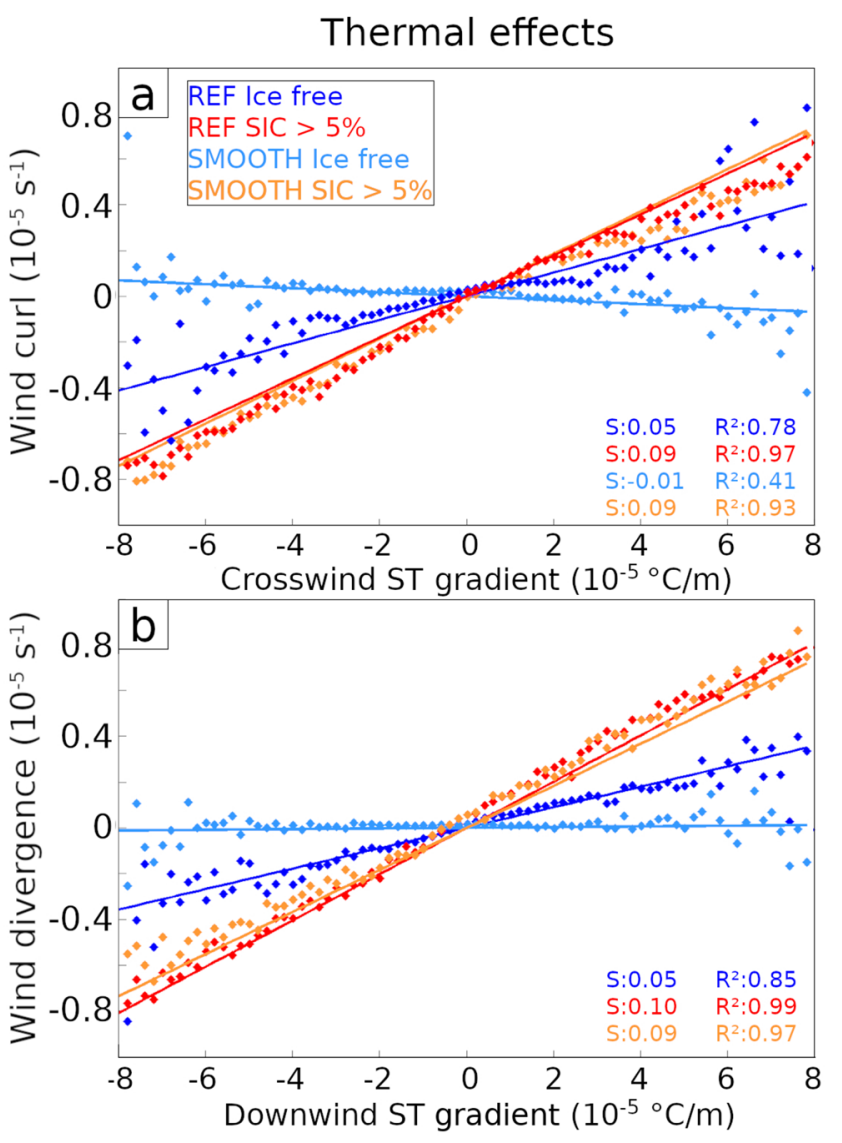

Fig. 5 Binned scatterplots of the small-scale anomalies of: a the crosswind surface temperature (ST) gradient and the wind curl, $\mathbf{b}$ the downwind ST gradient and the wind divergence, $\mathbf{c}$ the geostrophic current vorticity and the wind curl, $\mathbf{d}$ the geostrophic currents vorticity and the ocean stress curl. Bin widths are $1 \times 10^{-6}{ }^{\circ} \mathrm{C} / \mathrm{m}$ for temperature gradients and $1 \times 10^{-6} \mathrm{~s}^{-1}$ for the geostrophic vorticity. Each marker corresponds to the average of all simulated points within the

sea surface height using the geostrophic balance. The relationships between the mesoscale anomalies of these fields are depicted in Fig. 5c, d. As for the thermal effect, we compute one relationship for the ice-free $(S I C=0)$ and one for the ice-covered $(S I C>0.05)$. Note that the "stress" is the cell average of the wind stress and ice stress on the ocean (hereafter "ocean stress"). In the ice-covered ocean, it thus also incorporates the dynamical interactions between the ocean and the sea ice.

For the ice-free case, REF simulates a positive relationship between the current vorticity and the wind curl, in agreement with previous results (Renault et al. 2016). This can be explained by the negative relationship between the current vorticity and the ocean stress curl. The friction of eddies against the atmosphere leads to a stress curl opposed to the ocean currents. This results in a modification of the air-sea stress and induces a wind curl in the same direction as the ocean currents vorticity. However, there are no
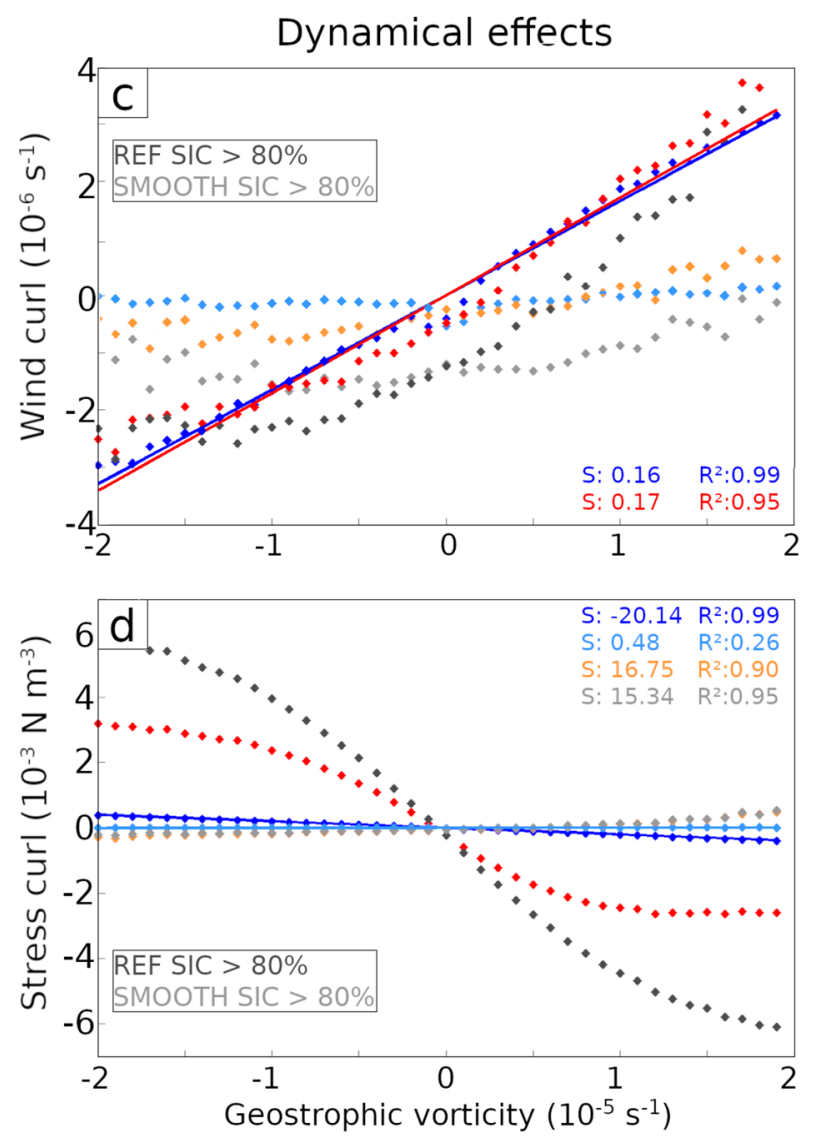

bin range. The binned scatter plots are built from daily outputs over the period 2012-2013. For the "ice free" relationships, only the pixels with a sea ice concentration (SIC) equal to zero are considered. Linear regressions on the bin averages are indicated when such a relationship exists. The slopes (S) and regression coefficients (R) are indicated on each panel. The spreads within each bin are indicated in Supplementary Figs. B.3 and B.4

significant relationships between the geostrophic vorticity and the wind divergence (not shown) as was previously reported by Renault et al. (2019). The presence of sea ice does not seem to affect the relationship between the surface current vorticity and the wind curl, but the confidence in the relationship is low as the spread within each bins becomes large over the ice-covered ocean (Supplementary Fig. B.4b, c). The relationship between the geostrophic vorticity and the stress curl is amplified. Two reasons can be given to explain the strength of the vorticity-stress curl relationship in the ice-covered ocean. First, the ocean-ice drag coefficient is larger than the ocean-air one. Also, ocean currents and sea ice velocities have the same order of magnitude, making sea ice more sensitive to ocean currents. Yet, the relationship gets weaker for a high absolute current vorticity. This suggests that ocean currents drive sea ice motion in intense eddies, which leads to a saturation of the ice-ocean stress. By taking only the pixels where $S I C>0.8$ (dark gray 
markers of Fig. 5d) likely representing more resistant sea ice, the effect of currents vorticity on stress curl weakens for high absolute vorticity but does not saturate anymore. A potential explanation is that a more compact sea ice cover offers a stronger resistance to the deformation generated by small-scale oceanic currents. Comparing geostrophic vorticity to sea ice velocity curl (Supplementary Fig. B.5) shows that weak sea ice $(S I C<0.8)$ closely follows rotating geostrophic currents, but that more compact sea ice $(S I C>0.8)$ does not for high geostrophic vorticity values. The alignment of sea ice velocities with ocean currents for weak sea ice cover can also explain why the vorticity-wind curl relationship (Fig. 5c) is not affected by the presence of weak sea ice. Indeed, the eddies will affect the air-ice momentum transfer by generating a curl of sea ice velocities.

In the SMOOTH simulation, the dynamical effect vanishes, as illustrated by the flat curves of Fig. $5 \mathrm{c}$. This is due to the removal of the contribution of small-scale currents to ocean stress. For the ice-covered ocean, SMOOTH exhibits a positive relationship between the vorticity and the stress curl, which might indicate the forcing of the ocean circulation by the large-scale sea ice curl. The relationships between ice-free surface temperature gradients and wind divergence become null, and the one with the wind curl becomes negative (Fig. 5a, b). It is not the case for the coupling between surface temperature gradient and wind divergence or curl in the presence of sea ice (orange markers in Fig. 5a, b). In SMOOTH, small-scale heterogeneities in the sea ice cover are not filtered out. Thus, there are still small-scale surface temperature gradients that can drive small-scale interactions in the ice-covered regions.

\subsection{Imprint of eddies on the sea ice, atmosphere and ocean}

In the previous section, we have described the mechanisms of atmosphere-sea ice-ocean coupling for general mesoscale structures. The origins of small-scale heterogeneity in the ocean surface and sea ice characteristics can be diverse (eddies, leads, local air-sea fluxes). Here, we focus on the imprint of ocean eddies. To do so, we apply the eddy tracking and analysis method described in Sect. 2.5 to the daily SSH of the REF simulation. Between the 1st of January 2012 and 31st of December 2013, we detected $\sim 5100$ occurrences of cyclonic eddies and $~ 3400$ occurrences of anticyclonic eddies (approximately 7 cyclonic eddies and 5 anticyclonic eddies each day). Note that a single eddy can be detected and counted several days in a row. As illustrated in Fig. 6, anticyclonic and cyclonic eddies are relatively uniformly distributed apart from the peak in cyclonic eddy frequency near $64^{\circ} \mathrm{S}$ and the peak of anticyclonic eddy frequency near $63^{\circ} \mathrm{S}$.

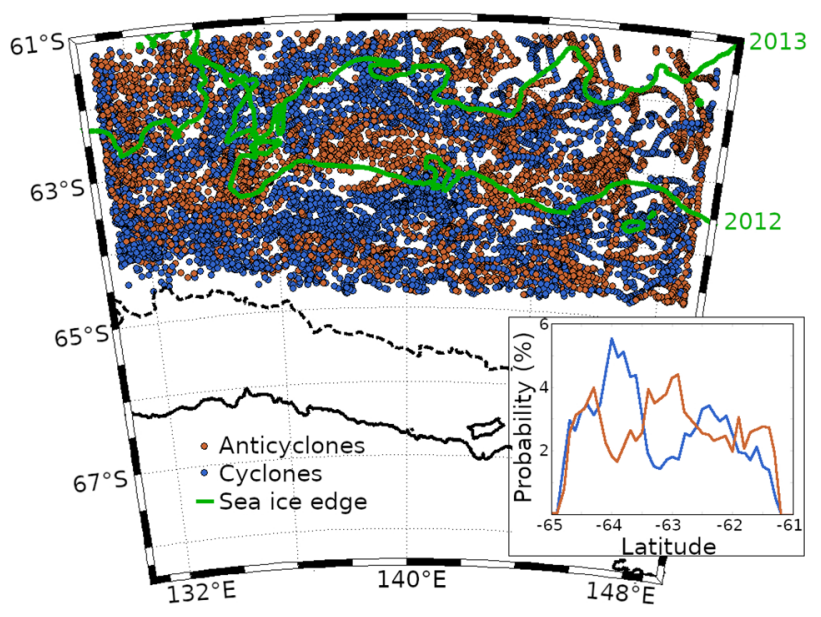

Fig. 6 Location of eddies detected in REF between 1st of January 2012 and 31st of December 2013. The green lines indicate the maximum sea ice extent for years 2012 and 2013. The coastline is indicated as a thick black line and the $1200 \mathrm{~m}$ isobath as a dashed black line. The insert represent the meridional distribution of eddies

First, we investigate the effects of eddies on sea ice. To do so, we consider here only the eddies with a mean sea ice concentration greater than 0.4 within 3 eddy radius. Most of the ice-covered eddies are encountered close to the ice edge, as shown by the northward decrease in sea ice concentration (Fig. 7a, b). Anticyclonic eddies are associated with negative SIC anomalies, while cyclonic eddies are associated with positive ones. The mean sea ice production rate north and alongside the eddies is negative, as ice-covered eddies are mostly encountered in the north of the ice pack (Fig. 7c, d). The imprint of eddies is overlaid on this large-scale trend. There is a stronger melt $(-1$ $\mathrm{cm} /$ day within the eddy core compared to $-0.2 \mathrm{~cm} /$ day outside) in anticyclonic eddies and a lower melt or even freezing ( $+0.6 \mathrm{~cm} /$ day on average) above cyclonic eddies. Cyclonic eddies thus enable the formation of sea ice further north where sea ice should normally melt, but this is compensated by increased melt on the north of cyclonic eddies.

We separate the sea ice concentration trend into its thermodynamical and dynamical components in Fig. 7e, f, g, h. As for the sea ice growth rate anomalies, cyclonic and anticyclonic eddies have an opposite imprint on the thermodynamical SIC trend. The thermodynamical SIC trend is negative above anticyclonic eddies and positive above cyclonic eddies. This can be related to the sea surface temperature anomalies of mesoscale eddies, but also to Ekman pumping generated by the eddies' friction on the sea ice (discussed later). These anomalies are compensated by the imprint of eddies on the dynamical SIC trend. The sea ice converges above anticyclonic eddies (as previously described by Manucharyan and Thompson (2017)) and diverges above 

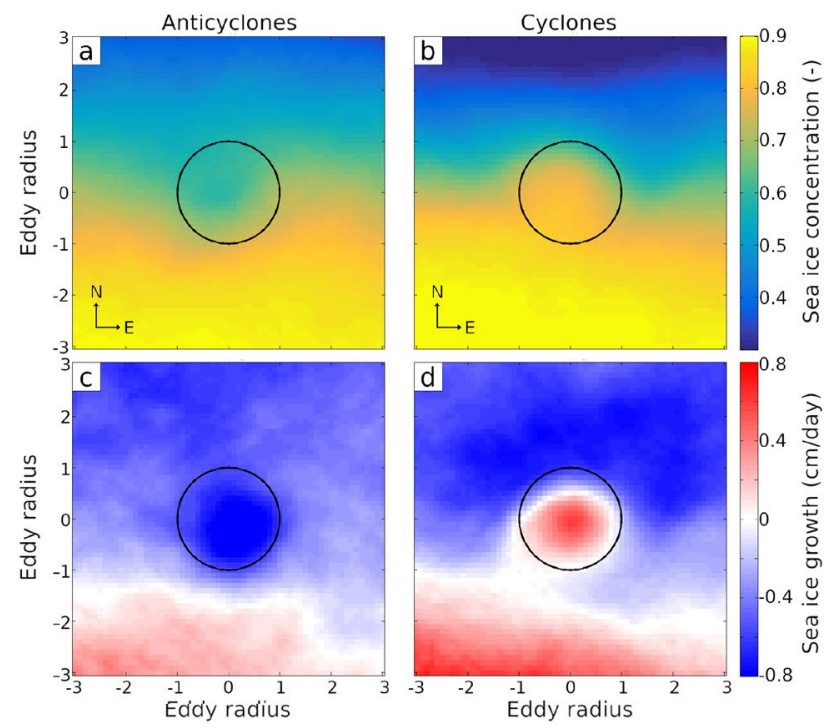

Fig. 7 Composites of the eddies' imprint on the sea ice concentration $(\mathbf{a}, \mathbf{b})$, sea ice growth rate $(\mathbf{c}, \mathbf{d})$, sea ice concentration thermodynamical $(\mathbf{e}, \mathbf{f})$, and dynamical $(\mathbf{g}, \mathbf{h})$ trends simulated in REF. Only the eddies with a sea ice concentration averaged within 3 eddy radius larger than 0.4 are accounted for. Anticyclonic eddy (warm core) and cyclonic eddy (cold core) are shown on the left and right columns of

cyclonic eddies. Cyclonic eddies are also associated with a northward sea ice advection, as seen by the positive dynamical SIC trend in Fig. 7h. The advected sea ice likely encounters warmer waters north of the ice edge, leading to intensified melt (Fig. 7d, f).

We apply the same diagnostics to detect the imprint of eddies on air-sea fluxes and on surface air properties (Fig. 8) in the REF simulation. On average, the imprint of ice-free eddies on near-surface air temperature or humidity is almost indistinguishable $\left(<0.05{ }^{\circ} \mathrm{C}\right.$ and $\left.<0.05 \mathrm{~g} / \mathrm{kg}\right)$. The imprint of eddies becomes significant for ice-covered eddies, the atmosphere is warmer $\left(+0.3{ }^{\circ} \mathrm{C}\right)$ and moister $(+0.3 \mathrm{~g} / \mathrm{kg})$ over ice-covered anticyclonic eddies. The sign of the anomalies is reversed for ice-covered cyclonic eddies. The temperature and moisture anomalies originate from the imprint of eddies on latent and sensible heat fluxes (Fig. 8e, f). These stronger anomalies are coherent with the negative (positive) sea ice concentration anomalies of anticyclonic (cyclonic) eddies, but could also illustrate the stronger sensitivity of the atmosphere to small-scale heterogeneity of surface conditions in ice-covered regions described earlier (Fig. 5).

The influence of eddies can also be observed on the winds. The presence of anticyclonic eddies leads to wind intensification, while cyclonic eddies lead to the opposite response (Fig. 8c). As with air temperature, the imprint is stronger for ice-covered than for ice-free eddies, which can be related to the stronger changes in air temperature for ice-covered eddies. Two mechanisms are often proposed to explain the modulation of wind speed by mesoscale eddies.
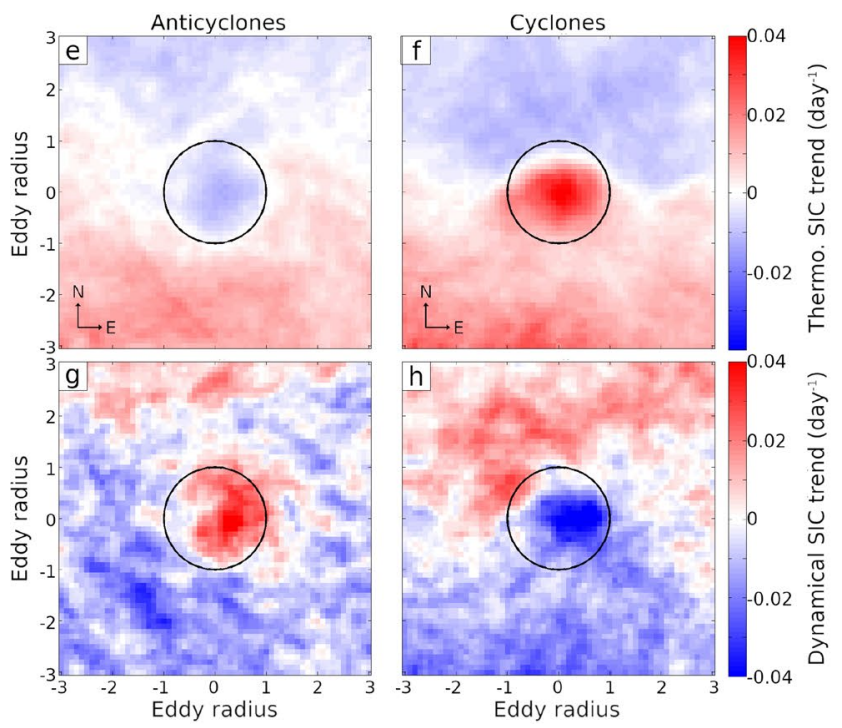

each sub-figure, respectively. Each eddy has been scaled with respect to its radius but the orientation of eddies is not modified. Composites are built from $01 / 01 / 12$ to $31 / 12 / 13$. A circle of one eddy radius is drawn on each panel. The inter-eddy variability can be found in Supplementary Fig. B.6

The first one involves a modification of the vertical momentum transfer due to changes in atmosphere stability associated with the warming/cooling effect of eddies. The second one is a modification of local pressure (due to changes in air density), which can drive local winds. The imprint of eddies on surface pressure (not shown) is either null or uncorrelated to the simulated changes in wind speed. The effects of eddies on wind speed simulated in REF are most likely imputable to changes in vertical momentum transfer. This is in agreement with the imprint of eddies on the planetary boundary layer (Fig. 8d). The planetary boundary layer (PBL) is on average thicker above anticyclonic eddies than above cyclonic eddies. Thicker PBL enables a stronger downward momentum transfer and stronger winds above anticyclonic eddies.

The coupled model shows that mesoscale eddies affect air temperature and wind speed off Adélie Land. The imprint on air temperature or wind speed remains relatively weak, but the latter is in agreement with the imprint on wind speed observed by Frenger et al. (2013). However, the influence of eddies on the atmosphere quickly vanishes as we move away from the surface. Despite the imprint on the height of the PBL, we have not detected any imprint on the cloud cover or precipitation rates in our simulation. Besides, the atmospheric response to eddies suggests the existence of small-scale feedbacks. Air warming (cooling) above anticyclonic (cyclonic) eddies reduces the air-surface temperature contrast and thus, the turbulent heat fluxes. The modification of wind speeds due to the presence of eddies can amplify or on the contrary dampen the temperature contrast diminution 

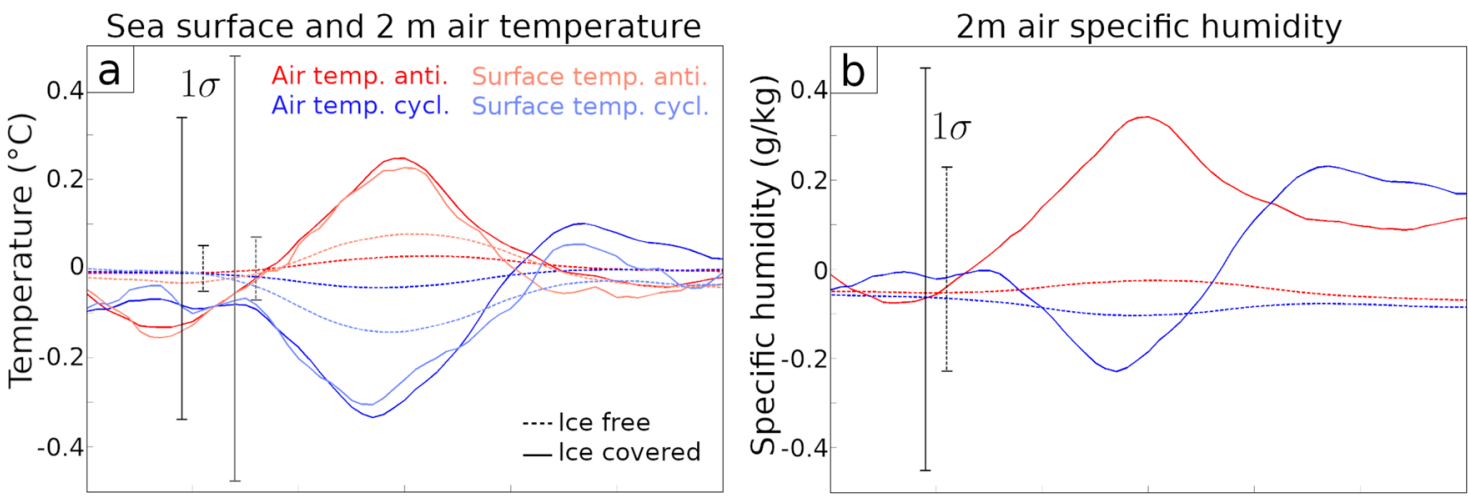

$10 \mathrm{~m}$ wind speed
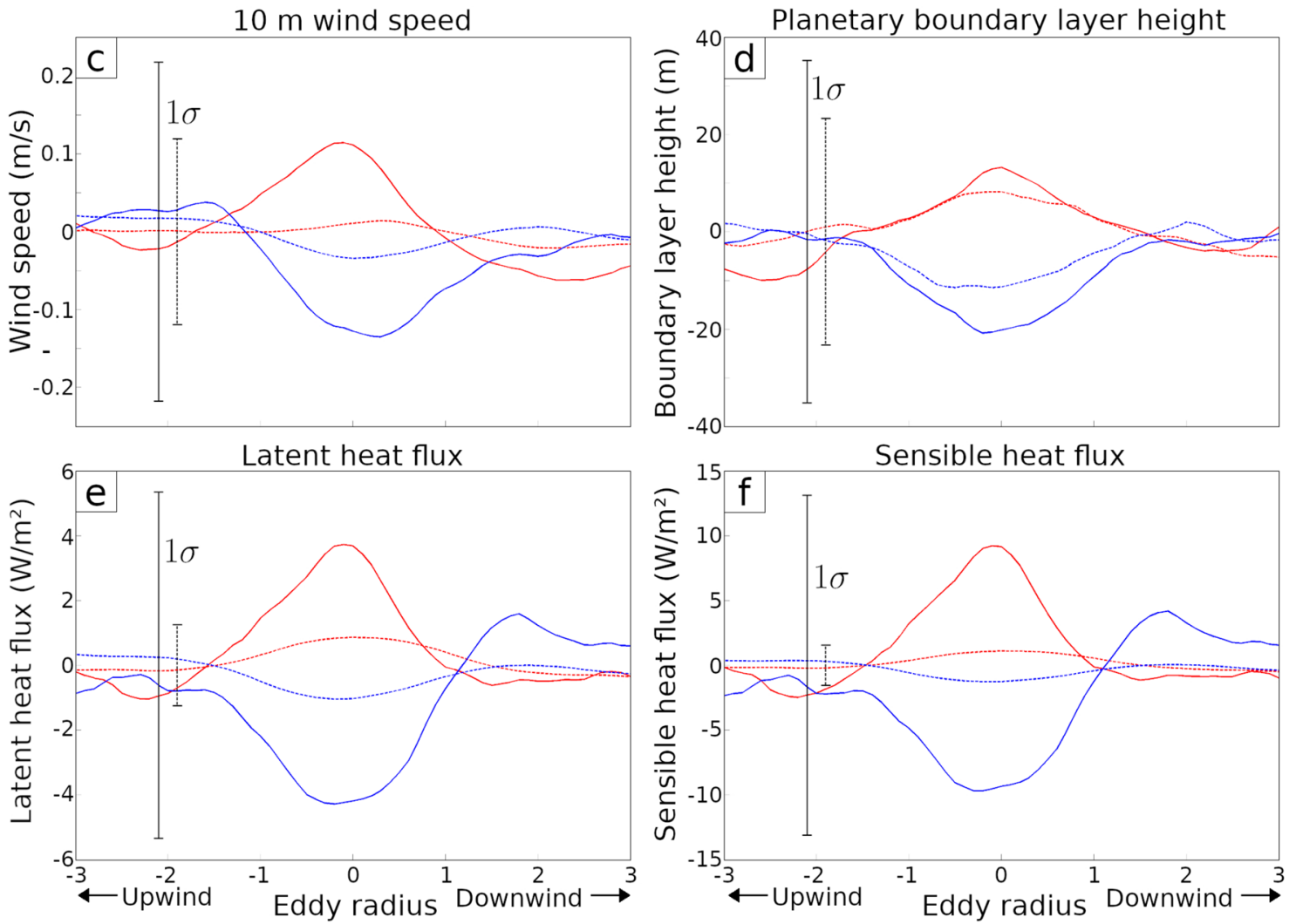

Fig. 8 Downwind transects of the imprint of eddies on the mesoscale anomalies of surface conditions, heat fluxes, and atmosphere. A negative (positive) eddy radius corresponds to the upwind (downwind) side of the eddies. a Surface temperature (weighted average of the ocean and sea ice temperatures, light blue and pink) and $2 \mathrm{~m}$ air temperature (red and blue), b $2 \mathrm{~m}$ air specific humidity, c $10 \mathrm{~m}$ wind speed, $\mathbf{d}$ planetary boundary layer height, $\mathbf{e}$ latent heat flux, and f sensible heat flux. A positive heat flux means an energy loss by the surface. The mesoscale anomalies of each field were first extracted following the method described in Sect. 2.4 and the composites were

effect, as stronger (weaker) winds would intensify (lower) the heat loss above anticyclonic (cyclonic) eddies.

An interesting result is the higher sensitivity of the atmosphere to eddies in ice-covered areas which might be related to the stronger air-sea coupling in presence of sea ice described in Sect. 3.2. As sea ice limits air-sea fluxes,

built by averaging the anomalies found above the eddies. Eddies were resized with respect to their radius and rotated to be aligned with the local wind. Separated downwind transects are computed for anticyclonic eddies (red or pink) and cyclonic eddies (blue or light blue). The distinction is also done between ice-free (dashed line) and icecovered $(S I C>0.4$, solid line) eddies. The vertical black lines represent the standard deviation (centered around zero) of the composites, computed at the eddies' center $(x=0)$ in REF (solid line) and SMOOTH (dashed line). The composites are computed using daily outputs from REF between 2012 and 2013

the anomalies of sea ice concentration associated with mesoscale eddies likely intensify the atmosphere's response to the presence of a mesoscale eddy. In addition, sea ice can reach lower temperatures than the sea surface, leading to stronger surface temperature gradients than over ice-covered than over ice-free eddies. However, it seems that the 
difference between surface temperature and near-surface air temperature is similar between ice-covered and ice-free eddies in the REF simulation (not shown). The higher sensitivity of the atmosphere to ice-covered eddies could arise from the differences in heat transfer coefficient between the ocean and sea ice. Another potential cause might be the presence of a thermal inversion over the sea ice, increasing the sensitivity of surface air to surface heat fluxes.
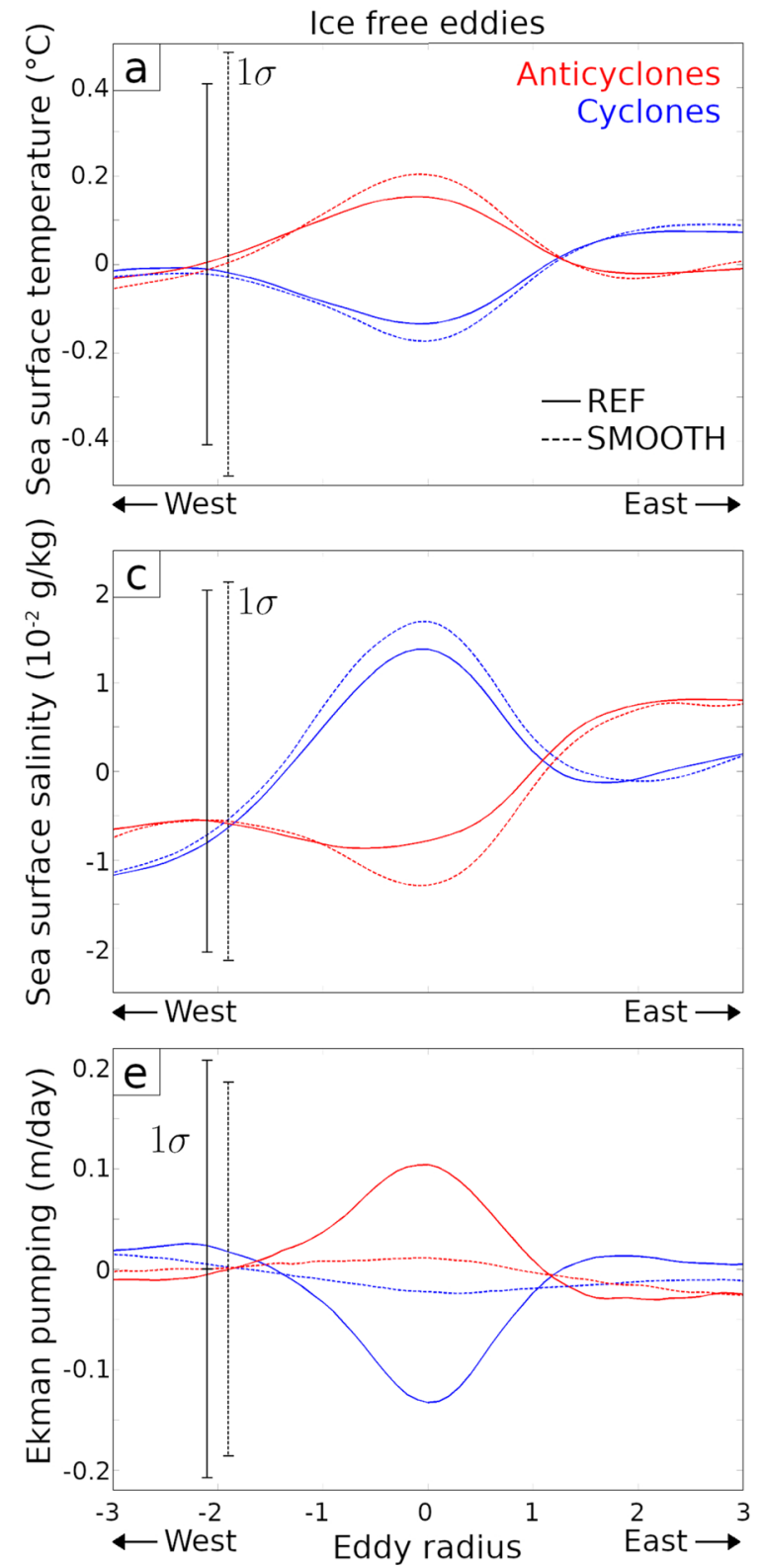

Fig. 9 Mean zonal sections of the mesoscale anomalies of the sea surface temperature (top row), sea surface salinity (middle row), and Ekman pumping (bottom row) simulated in REF and SMOOTH. The composites are built as in Fig. 8 but the eddies were not aligned with the local wind here. Therefore, a negative (positive) eddy radius cor-
Finally, we investigate the eddies signature on ocean surface conditions and how it is affected by the interactions of eddies with the atmosphere or sea ice by comparing the eddies' surface characteristics in REF and SMOOTH. In both simulations, anticyclonic eddies have a warm and fresh core and cyclonic eddies a cold and saline core, whether they are covered by sea ice or not (Fig. 9a-d). This signature differs from the warm and saline/cold and fresh anomalies observed by Frenger et al. (2015), and the SST signature
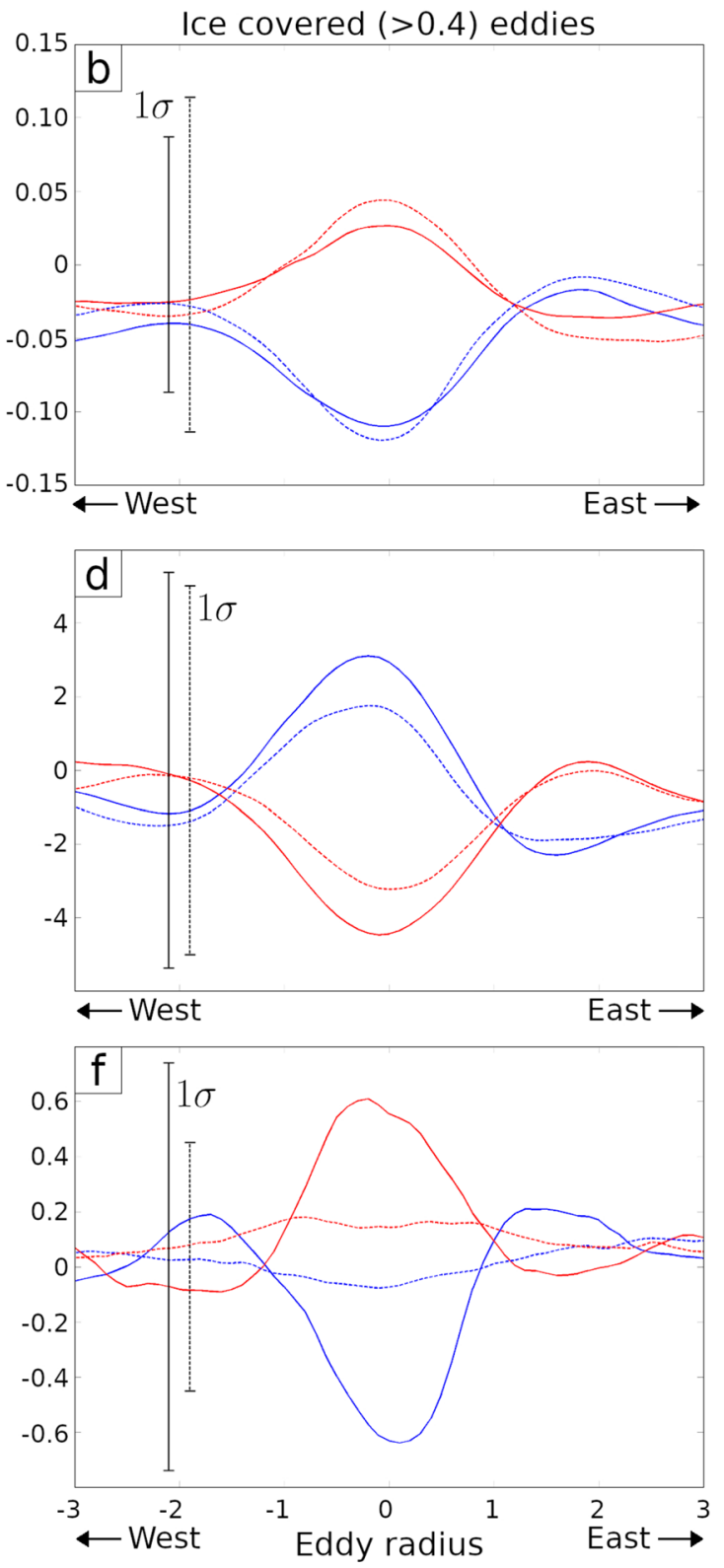

responds to the west (east) side of the eddies. Computed for ice-free (left) and ice-covered (SIC $>0.4$, right) eddies. The vertical black lines represent the standard deviation (centered around zero) of the composites, computed at the eddies' center $(x=0)$ in REF (solid line) and SMOOTH (dashed line) 
of eddies simulated is approximately half the one observed by Frenger et al. (2015) (they however consider eddies in the whole Southern Ocean and likely do not detect eddies as small as the one accounted for here). In the absence of sea ice, the interactions of eddies with the atmosphere act to dampen their thermal and saline structure. The signature of ice-free eddies on surface temperature or salinity is indeed weaker by $20 \%$ in REF than in SMOOTH. For icecovered eddies, the temperature anomaly is also dampened in REF compared to SMOOTH, but the salinity anomaly is enhanced. This can be related to the increase (decrease) of sea ice production over cyclonic (anticyclonic) eddies. In addition to the anomalous heat and salt flux, the friction of eddies against the surface generates Ekman suction in anticyclonic eddies and Ekman pumping in cyclones ones (Fig. 9e, f), which can affect the surface properties of the ocean. The Ekman suction/pumping is stronger over icecovered eddies (up to $0.6 \mathrm{~m} /$ day) compared to ice-free eddies $(0.1 \mathrm{~m} /$ day $)$ and is close to the values obtained by Gupta et al. (2020). Eddy-driven atmosphere-sea ice-ocean interactions thus contribute to vertical exchanges, especially in the ice-covered ocean.

\section{Effects of eddies on momentum and buoyancy fluxes at the ocean surface}

\subsection{Momentum transfer and kinetic energy budget}

In the previous section, we have shown that eddies were associated with small-scale variability of ocean, sea ice, and atmosphere properties. We now investigate how the aforementioned interactions affect the large-scale atmosphere-sea ice-ocean buoyancy and momentum fluxes.

The friction of mesoscale ocean currents on the atmosphere or sea ice extracts energy from the eddies. This process is at play in REF (as illustrated in Fig. 5) but not in SMOOTH, and can affect the oceanic kinetic energy budget. The ocean kinetic energy (KE) time series in REF and SMOOTH are shown in Fig. 10. Total KE in REF experiences a strong variability at the sub-annual time scale. It has two maxima, one in May and one in November (though being weaker in 2013). The total ocean kinetic energy is higher in SMOOTH, and the seasonal variability is less pronounced. We compute the KE source originating from the eddying component of the surface stress following Renault et al. (2016), i.e. as $\mathrm{FeKe}=\frac{1}{\rho_{0}}\left(\tau_{x} U_{\text {oce }}+\tau_{y} V_{\text {oce }}\right)$, with $\rho_{0}=1035 \mathrm{~kg} / \mathrm{m}^{3}$ the reference density of seawater, $\tau_{x}$ and $\tau_{y}$ the eddy surface stress zonal and meridional components (average of wind stress and sea ice stress) and $U_{\text {oce }}$ and $V_{\text {oce }}$ the eddying components of the zonal and meridional ocean surface current velocities. As in Renault et al. (2016), the
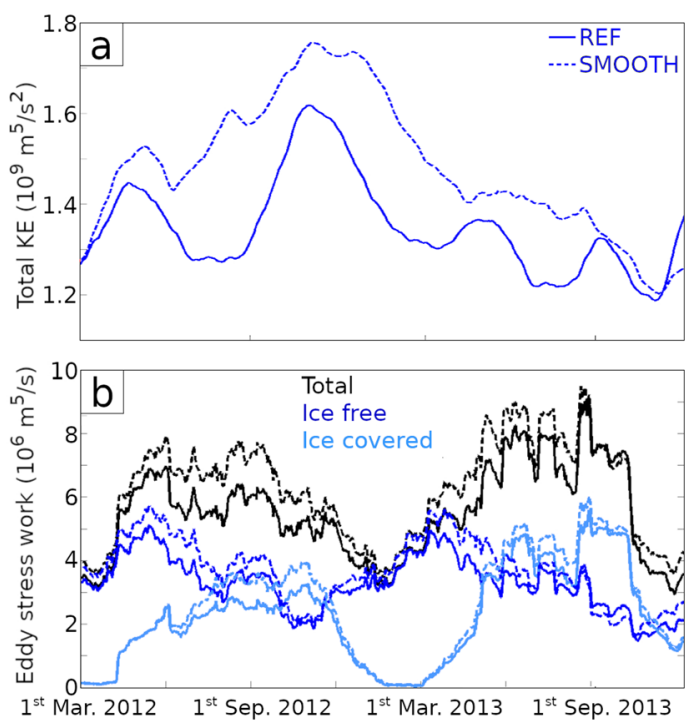

Fig. 10 a Upper $200 \mathrm{~m}$ ocean kinetic energy north of $65^{\circ} \mathrm{S}$ in REF and SMOOTH. b Eddy stress work north of $65^{\circ} \mathrm{S}$ for the whole area (black), the ice-free (SIC $=0$ ) area (red), and the ice-covered $($ SIC $>0.05)$ area (blue). REF and SMOOTH are denoted with solid and dashed lines, respectively. A common sea ice mask is used for the computation of the eddy stress work for ice-free and ice-covered oceans in REF and SMOOTH. A 60 day moving average was applied to the time series

eddying components of the surface stress or surface current velocities are computed as the departure from the 2-year average (without filtering the seasonal cycle). The work exerted by friction at the top of eddies (hereafter eddy stress work) in REF and SMOOTH are shown in Fig. 10b. There is a clear seasonal cycle with a maximum kinetic energy input during the winter season, as wind speeds are generally stronger. The eddy stress work is higher during winter in SMOOTH, especially in 2012. This might be one of the reasons for the lower total KE in REF. The eddy-killing effect is roughly equally efficient over the ice-free ocean than over the ice-covered ocean with a $10.2 \%$ and $12.8 \%$ of eddy stress work decrease between REF and SMOOTH, respectively. Overall, the energy input through eddy stress work is decreased by $11 \%$, and the ocean KE by $8.2 \%$ when eddydriven atmosphere-sea ice-ocean interactions are turned on.

\subsection{Freshwater and buoyancy fluxes}

By forming close to the coast and melting offshore, the sea ice redistributes freshwater at the Southern Ocean surface. As eddies affect the ocean interactions with the sea ice and the atmosphere, they can also affect the freshwater budget of the ocean. The total sea ice production (Fig. 11, black curve) and the total sea ice volume (not shown) are not affected by the presence of eddies. But, this hides compensating changes in sea ice growth and melt. Indeed, REF produces more sea 


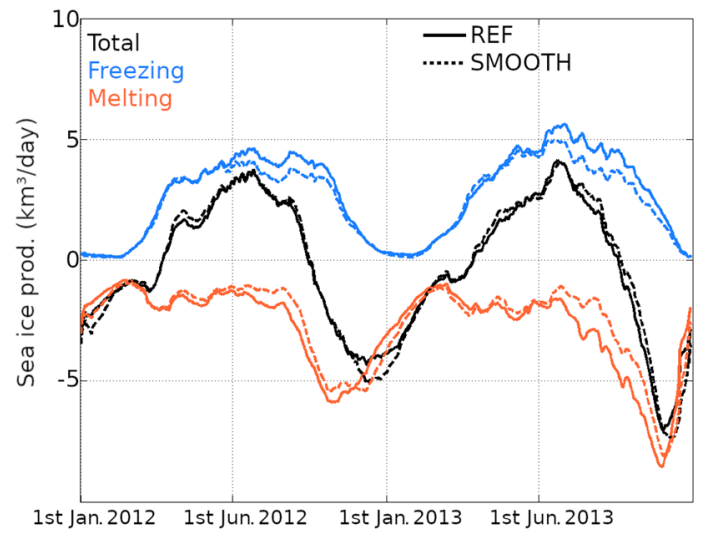

Fig. 11 Time series of the total thermodynamical sea ice volume trend (black), sea ice freezing (teal) and melting (orange) simulated in REF and SMOOTH

ice than SMOOTH (Fig. 11), which is compensated by larger melt. The lowering of sea ice freezing and melting in SMOOTH occurs from early July to September, or between the maximum sea ice extent and the summer. Eddies have no clear effect during the onset of the seasonal ice cover (from March to June). It is only when sea ice advances far enough offshore that it can encounter mesoscale eddies. If the total freshwater flux associated with sea ice melt/freeze is similar between the two simulations, its effects on the ocean are not necessarily compensated. The brine rejection due to seawater freezing destratifies the water column and impacts the subsurface ocean, which is not the case for sea ice melting. In addition, melting and freezing do not occur at the same place, thus the spatial distribution of the freshwater fluxes may be modified.

The meridional distribution of the sea ice melting differs between the two simulations (Fig. 12a). The amount of sea ice melting north of $62.5^{\circ} \mathrm{S}$ is increased by $15 \%$ in REF compared to SMOOTH. To support the larger melt rates north of $63^{\circ} \mathrm{S}$ in REF, additional sea ice transport is required. There is indeed an increased northward sea ice advection in REF (Fig. 12b): starting from $63.5^{\circ} \mathrm{S}$, the northward sea ice volume advection is higher by $2 \times 10^{3} \mathrm{~m}^{3} / \mathrm{s}$ in REF. This results in higher melting in the northern half of the domain, leading to stronger ocean stratification (Fig. 12c). Another effect of the lower northward sea ice export in SMOOTH is its accumulation inside the ice pack, leading to the intensified melt near $63.5^{\circ} \mathrm{S}$.

The redistribution of sea ice and the modulation of air-sea heat fluxes by eddies can affect the surface buoyancy fluxes and the transformation of water masses off Adélie Land. Water masses undergoes two types of transformation in the Southern Ocean: either an increase in density dominated by brine rejection and ocean cooling, or an opposite density decrease dominated by sea ice melt, ocean warming,

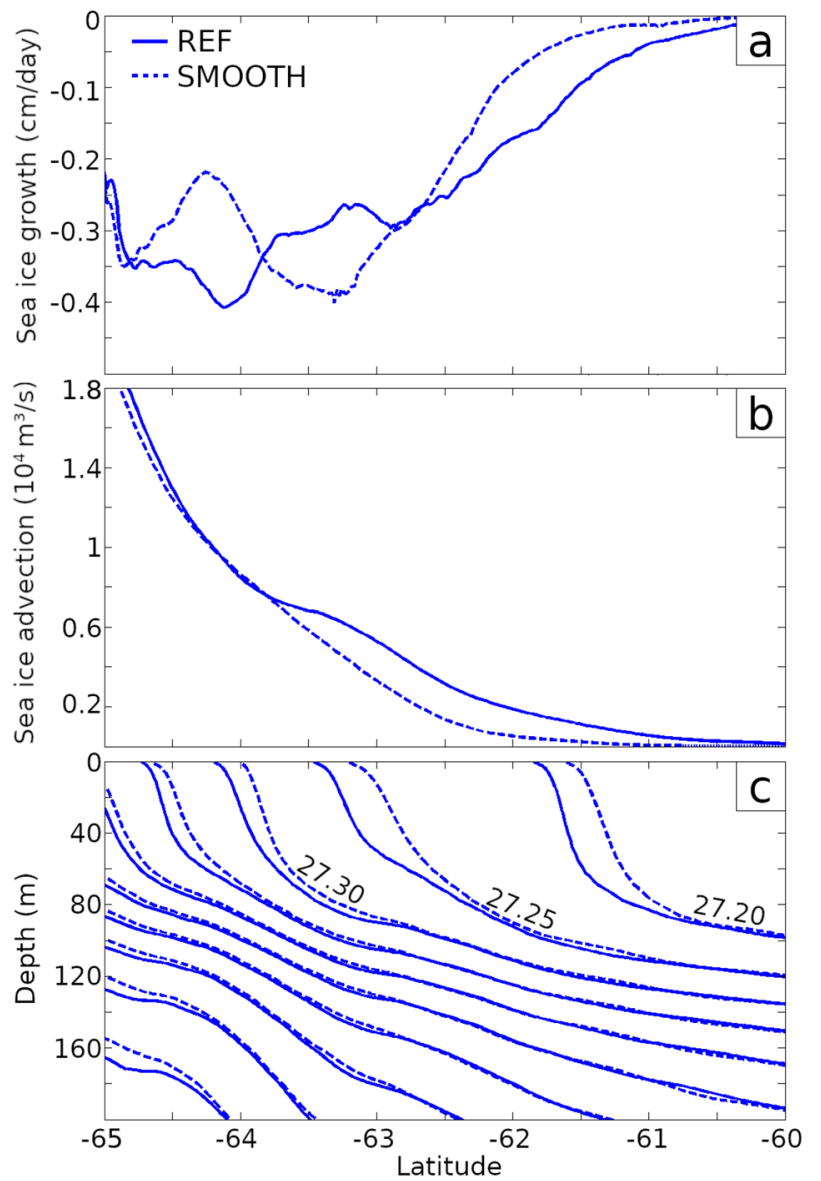

Fig. 12 Meridional profiles of: a mean sea ice growth rate, $\mathbf{b}$ total meridional sea ice advection (positive northward), and c, ocean potential density (referenced to the surface) contoured every $0.05 \mathrm{~kg} /$ $\mathrm{m}^{3}$ as simulated in REF and SMOOTH over the year 2013

and precipitation. We compute the water mass transformations by surface fluxes following the method proposed by Walin (1982) and used for the Southern Ocean in Abernathey et al. (2016) and Jeong et al. (2020). The water mass transformation rate $\Omega$ is defined as $\Omega(\sigma, t)=\frac{1}{\sigma_{k+1}-\sigma_{k}} \iint_{A}\left(\frac{\alpha Q}{C_{p} \rho_{0}}+\frac{\beta S F}{\rho_{0}}\right) d A . \sigma$ is the seawater potential density referenced to the surface, $\alpha$ and $\beta$ the thermal expansion and haline contraction coefficients, $Q$ the surface heat flux, $C_{p}$ the thermal capacity of seawater at constant pressure $\left(C_{p}=3994 \mathrm{~J} / \mathrm{kg}{ }^{\circ} \mathrm{C}\right), S$ the surface salinity, $F$ the freshwater flux, $\rho_{0}$ the reference density of seawater, and $A$ the area of the ocean surface with $\sigma_{k}<\sigma<\sigma_{k+1}$. We use a $\sigma$ scale with a bin width of $0.1 \mathrm{~kg} / \mathrm{m}^{3}$ below $26.9 \mathrm{~kg} / \mathrm{m}^{3}, 0.05$ $\mathrm{kg} / \mathrm{m}^{3}$ between $26.9 \mathrm{~kg} / \mathrm{m}^{3}$ and $27.5 \mathrm{~kg} / \mathrm{m}^{3}$, and $0.01 \mathrm{~kg} / \mathrm{m}^{3}$ above $27.5 \mathrm{~kg} / \mathrm{m}^{3}$ to increase the resolution for the high density water masses. We compute a transformation rate for the freshwater flux associated with sea ice melting or freezing and for E-P (rainfall and snowfall minus the evaporation). We also compute a transformation rate due to heat fluxes, 


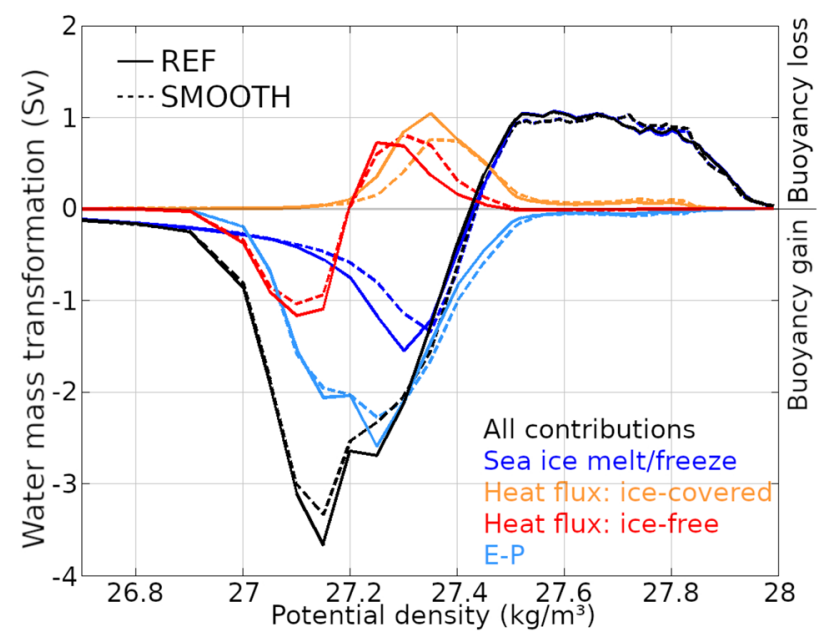

Fig. 13 Water mass transformation rate per density class in REF (solid lines) and SMOOTH (dashed lines). The total contribution (black line) is the sum of the buoyancy flux due to sea ice freezing or melting (blue), the buoyancy flux associated with heat fluxes (latent, sensible, longwave, and shortwave) for the ice-free (red) and ice-covered (orange) cases, and the precipitation over the ocean (teal)

which is separated into the ice-free and ice-covered $($ SIC $>0.05)$ cases.

The water mass transformation rates simulated in REF and SMOOTH are illustrated in Fig. 13. The total transformation (black curves) shows the expected buoyancy loss by dense waters $\left(\sigma>27.4 \mathrm{~kg} / \mathrm{m}^{3}\right)$ and the buoyancy gain of lighter waters $\left(\sigma<27.4 \mathrm{~kg} / \mathrm{m}^{3}\right)$. The buoyancy loss of dense waters is dominated by the brine flux, with a secondary role of heat loss in the ice-covered ocean for relatively lighter waters. The gain of buoyancy is distributed between the freshwater and heat fluxes from sea ice melting, the surface warming for the ice-free ocean, and precipitation. The surface transformation of water masses denser than $\sigma>27.4$ $\mathrm{kg} / \mathrm{m}^{3}$ is weakly affected by the eddies. Most of the surface transformation of dense waters takes place on the continental shelf, where the model is not eddy-resolving. The transformation of intermediate waters $(27<\sigma<27.4 \mathrm{~kg} /$ $\mathrm{m}^{3}$ ) is reduced in SMOOTH compared to REF. This means that intermediate density waters receive weaker buoyancy fluxes in SMOOTH. Buoyancy loss due to heat fluxes in the ice-free ocean is higher in SMOOTH than in REF. There is an opposite effect for the ice-covered ocean. This results from the lowering of the sea ice extent in response to weaker northward sea ice advection in SMOOTH. Buoyancy gain through heating in the ice-free ocean is slightly decreased in SMOOTH. The contribution of sea ice melt to water masses transformation is also lowered. We note a slight decrease in buoyancy gain due to E-P. As seen in Fig. 12, eddies contribute to the northward export of sea ice. In SMOOTH, less sea ice is available for melting in the intermediate density waters encountered in the north of the Adélie Land sector. This leads to a weaker freshwater flux and buoyancy gain. The combined effect of eddies is an increase of buoyancy loss or water mass transformation for the intermediate to low density waters. Thus, by redistributing the sea ice, eddies act to restratify the ocean and transform water masses in the upper branch of the thermohaline circulation.

\section{Discussion}

The present results reveal that eddies can affect the air-sea fluxes and the atmosphere in high latitudes of the Southern Ocean, even in the presence of sea ice. To our knowledge, it is the first time that the modulation of atmosphere-sea ice-ocean interactions by mesoscale eddies is described in a coupled model. Our results confirm the possibility for eddy-sea ice interactions through the mechanisms described by Manucharyan and Thompson (2017) and Gupta et al. (2020). As in those studies, the imprint of eddies on the sea ice originates from the dynamical and thermal forcing of eddies. The sea ice also affects the eddies in return, via the modulation of surface buoyancy fluxes or the mechanical slow down of eddies. We found that the eddy-driven sea ice advection explains most of the large-scale effects of eddies. The mechanism of Manucharyan and Thompson (2017) might be a key process governing the evolution of the MIZ and the ocean stratification in the Southern Ocean. Eddies are thought to contribute to ocean restratification by flattening tilted isopycnals (McWilliams 2008; Chanut et al. 2008). The eddy-driven sea ice advection can be a second mechanism by which eddies restratify the Southern Ocean. Gupta et al. (2020) suggested that eddy-ice pumping in anticyclonic eddies leads to upward heat flux and sea ice thickness reduction. The EIP seems to have a weaker effect in our simulations, which might be due to the higher proportion of cyclonic compared to anticyclonic eddies simulated off Adélie Land. Besides, we showed that the stress curl response to an increase of current vorticity saturated for eddies covered by weak sea ice. As we do not detect many eddies in the strong ice pack, the EIP simulated in our experiments is likely weaker than the one of Gupta et al. (2020).

Besides the imprint of eddies on the sea ice, we also explored how eddies modulate air-sea interactions with and without sea ice. For the ice-free ocean, we found that the dynamical and thermal mesoscale air-sea coupling are at play in our simulation (Chelton and Xie 2010; Renault et al. 2016). This illustrates a tight coupling between the ocean and atmosphere at the mesoscale despite the small eddy radius and swift winds of the Southern Ocean. One of our most striking results is the existence of mesoscale air-sea interactions despite the presence of sea ice. The 
response of the atmosphere to the presence of mesoscale eddies is even stronger above the ice-covered than above the ice-free ocean. Through both mechanisms, ice-free and ice-covered eddies affect the near-surface atmosphere. This opens the possibility of feedback. The air cooling above ice-covered cyclonic eddies likely increases the sea ice lifetime, increasing the potential for eddy-driven advection. A proper quantification of the atmosphere-sea ice-ocean feedback remains to be done. Our findings suggest that the eddy imprint on the atmosphere observed by Frenger et al. (2013) could be extended to the ice-covered ocean. However, we did not find imprints of eddies on the atmosphere away from the surface. The cooler surface or stronger atmosphere stratification in the southernmost Southern Ocean might inhibit the upward propagation of the surface anomalies in the atmosphere (Bailey and Lynch 2000; van Lipzig et al. 2002; Kittel et al. 2018). This could also be due to model limitations such as the hydrostatic approximation or the use of a vertical mixing scheme designed for the ice sheet. Further sensitivity experiments have to be carried out to clarify this issue.

The effects of eddies on atmosphere-sea ice-ocean interactions have several implications for the modeling and understanding of the polar climate and Southern Ocean dynamics. Most current global climate models do not resolve mesoscale eddies. While several effects of eddies on the ocean are parameterized in climate models, no parameterization exists to represent the effects of eddies on the atmosphere-sea ice-ocean interactions. We showed that eddies affect the freshwater redistribution by the sea ice and the ocean surface momentum fluxes. Freshwater fluxes are essential for the dynamics of the Southern Ocean, as they condition the ocean stratification and the rate of water masses transformation. Changes in freshwater fluxes could induce a modification of heat and carbon storage in the Southern Ocean, affect the sea ice (Bintanja et al. 2015), and modulate the thermohaline circulation (De Lavergne et al. 2014; Abernathey et al. 2016). On the other hand, the effects of eddies on momentum fluxes can have repercussions for the Southern Ocean dynamics. The modulation of air-sea momentum fluxes by eddies was suggested to drive multidecadal variability of the Southern Ocean (Le Bars et al. 2016). Finally, the effects of eddies on the polar atmosphere are mostly unknown. Foussard et al. (2019) suggested that eddies affect the large-scale atmospheric circulation in an idealized polar vortex. As we have shown, eddies also affect the atmosphere in an icecovered ocean. However, the imprint of eddies on the sea ice or atmosphere described in the present study remains relatively weak. There is no change in the total sea ice production if the interactions of eddies with the sea ice are turned off, the imprint on air-sea flux is lower than $10 \mathrm{~W} / \mathrm{m}^{2}$ leading to a temperature response of the order of
$0.2{ }^{\circ} \mathrm{C}$, and the effect on the atmosphere is limited to the lowermost layers. The role of eddies on air-sea momentum fluxes and sea ice advection is more important and might have large-scale consequences, but the effects remain of second-order compared to other sources of error in Climate Models. Some of our conclusions might have, however, been underestimated due to the prescription of lateral boundary conditions. A similar experiment other the whole Southern Ocean would enable us to better quantify the importance of the processes described in this study.

We expect that the mesoscale atmosphere-sea ice-ocean interactions simulated here off Adélie Land are at play elsewhere in the Southern Ocean. Yet, one of the particularities of the Adélie Land sector is the proximity of ACC jets to the continental shelf (Sokolov and Rintoul 2009). This likely explains the high eddy activity found in this region (Hausmann et al. 2017) and also the relatively low sea ice extent in this sector of Antarctica. High-resolution coupled models of the whole Southern Ocean would be needed to understand how the processes described here affect the large-scale ocean, sea ice, and atmosphere. Besides, even higher resolution models would be needed to understand the role of eddies in the lower-cell of the thermohaline circulation and the formation of Dense Shelf Waters (Stewart et al. 2018). The results presented here might be sensitive to modeling and diagnostic choices. We used the eddy detection method based on sea-level anomalies developed by Faghmous et al. (2015), but many other methods exists such as the one of Haller (2016) (used in Abernathey and Haller (2018) or Tarshish et al. (2018)) or the use of the Okubo-Weiss parameter (see Williams et al. (2011) or Souza et al. (2011)). Using sea-level anomalies implies that eddies are in geostrophic balance, which is not necessarily the case when approaching the submesoscale (McWilliams 2016). The hypothesis that the eddies simulated here are in geostrophic balance is supported by the fact that our model cannot resolve such submesoscale flows. Besides, Abernathey and Haller (2018) showed that the radius of eddies detected by the method of Haller (2016) were smaller than the ones detected using sea-level anomalies in Chelton (2013). Using another eddy detection method with different estimates of the eddy radius could modify the dependence of the eddy-driven anomalies to the distance from the eddy core presented here, but the amplitude of the anomalies should remain the same. Evaluating the strengths, weaknesses, and range of application of these methods for the high latitudes would be highly beneficial to pursue the investigation of mesoscale eddies' role in the Southern Ocean but is out of the scope of the present study. Besides, an assessment of the sensitivity of mesoscale atmosphere-sea ice-ocean interactions to the model parameters is also needed. For instance, the treatment of the sea ice rheology might influence the ability of sea ice to deform due to small-scale ocean currents. The choice of transfer 
coefficients for the atmosphere-sea ice-ocean fluxes could also affect small-scale atmosphere-sea ice-ocean interactions. In our experiments, the sea ice roughness lengths for air-ice or sea ice momentum fluxes are assumed to be constant. But they may vary with the sea ice concentration or the sea ice morphology (Lüpkes et al. 2012). We compute the sea surface roughness as a function of wind speed, but this relationship does not hold when waves interact with sea ice (Boutin et al. 2018). In addition, the choice of vertical mixing scheme in the atmosphere possibly impacts the smallscale air-sea interactions (Song et al. 2009). It is unclear now how to represent the boundary layer turbulence above the sea ice. MAR is adapted for the representation of the stable boundary layer over the Antarctic Ice Sheet and thus potentially underestimates the turbulence over the ocean. The response of the atmosphere to the eddies might also be different with a non-hydrostatic model as shallow convection may occur over sea ice leads or polynyas (Gryschka et al. 2008).

\section{Conclusion}

The Southern Ocean is a region of intense atmosphere-sea ice-ocean interactions with global repercussions. It is also a hotspot of mesoscale activity. Yet, the role of eddies in modulating atmosphere-sea ice-ocean interactions is poorly understood. In this work, we have assessed how mesoscale eddies affect atmosphere-sea ice-ocean interactions in the Adélie Land sector using a regional ocean-sea ice-atmosphere model. We found that eddies affect the sea ice motion and melting/freezing. For the first time, we showed that eddies also imprint the near-surface air temperature and wind speed in ice-covered regions. These imprints are due to the modulation of atmosphere-sea ice-ocean heat and momentum fluxes by the eddies. At the scale of the Adélie Land sector, the modulation of atmosphere-sea ice-ocean interactions by eddies has two major effects for the ocean and sea ice. First, eddies dampen the energy input to the ocean by surface stress, reducing the large-scale kinetic energy. Secondly, eddies redistribute the sea ice and contribute to its northward advection. This leads to higher freshwater fluxes favoring ocean restratification in the seasonal ice zone. These results suggest that there is a tight coupling between the atmosphere, ocean, and sea ice at the mesoscale which could have an influence on the sea ice drift and ocean circulation at larger scale.

The recent research about ocean eddies in polar regions suggests that they play a bigger role than previously thought. This represents an important issue for the modeling of climate. Most global climate models do not resolve mesoscale eddies (let alone eddies in polar regions), and the parameterizations of eddy effects are not accounting for the specific processes of polar regions. The knowledge gap is yet a great opportunity for scientific research, as it opens many questions. Understanding the effects of the mesoscale atmosphere-sea ice-ocean interactions on the whole Southern Ocean is crucial. It may impact the dynamics of the ACC, the storm track, the thermohaline circulation, and the ocean carbon and heat uptake. Further work is needed to understand how to simulate mesoscale atmosphere-sea ice-ocean interactions. Such effort would benefit from the development of observational capabilities at small spatial scales.

Supplementary Information The online version contains supplementary material available at https://doi.org/10.1007/s00382-021-06115-x.

Acknowledgements The authors would like to thank Camille Lique and Lionel Renault for fruitful discussions. The authors would also thank the two anonymous reviewers who contributed to the improvement of this manuscript. This research was conducted within the F.R.S.FNRS PDR T.0002.16 "Air-Ice-Ocean Interactions in Antarctica" and the PARAMOUR project, funded by the FWO and F.R.S.-FNRS under the Excellence of Science (EOS) program (Grant EOS O0100718F). Computational resources have been provided by the supercomputing facilities of the Université catholique de Louvain (CISM/UCL) and the Consortium des Équipements de Calcul Intensif en Fédération Wallonie Bruxelles (CÉCI) funded by the Fond de la Recherche Scientifique de Belgique (F.R.S.-FNRS) under convention 2.5020.11. The present research benefited from computational resources made available on the Tier-1 supercomputer of the Fédération Wallonie-Bruxelles, infrastructure funded by the Walloon Region under the grant agreement $\mathrm{n}^{\circ} 1117545$. N. Jourdain's contribution was supported by the CRiceS project, which received funding from the European Union's Horizon $\mathrm{H} 2020$ research and innovation program under grant agreement No 101003826 .

Funding This research was conducted within the F.R.S.-FNRS PDR T.0002.16 "Air-Ice-Ocean Interactions in Antarctica" and the PARAMOUR project, funded by the FWO and F.R.S.-FNRS under the Excellence of Science (EOS) program (Grant EOS O0100718F). N. Jourdain's contribution was supported by the CRiceS project, which received funding from the European Union's Horizon H2020 research and innovation program under grant agreement No 101003826.

Code and data availability The eddy tracking algorithm used in this study is available at https://github.com/jfaghm/OceanEddies. Model outputs are available upon request to the author.

\section{Declarations}

Conflict of interest The authors declare that they have no conflict of interest.

\section{Ethics approval Not applicable}

Consent to participate Not applicable

Consent for publication Not applicable

Open Access This article is licensed under a Creative Commons Attribution 4.0 International License, which permits use, sharing, adaptation, distribution and reproduction in any medium or format, as long as you give appropriate credit to the original author(s) and the source, 
provide a link to the Creative Commons licence, and indicate if changes were made. The images or other third party material in this article are included in the article's Creative Commons licence, unless indicated otherwise in a credit line to the material. If material is not included in the article's Creative Commons licence and your intended use is not permitted by statutory regulation or exceeds the permitted use, you will need to obtain permission directly from the copyright holder. To view a copy of this licence, visit http://creativecommons.org/licenses/by/4.0/.

\section{References}

Abernathey R, Haller G (2018) Transport by Lagrangian vortices in the Eastern Pacific. J Phys Oceanogr 48(3):667-685. https://doi. org/10.1175/JPO-D-17-0102.1

Abernathey RP, Cerovecki I, Holland PR, Newsom E, Mazloff M, Talley LD (2016) Water-mass transformation by sea ice in the upper branch of the Southern Ocean overturning. Nat Geosci 9(8):596-601

Agosta C, Amory C, Kittel C, Orsi A, Favier V, Gallée H, van den Broeke MR, Lenaerts JTM, van Wessem JM, van de Berg WJ, Fettweis X (2019) Estimation of the Antarctic surface mass balance using the regional climate model MAR (1979-2015) and identification of dominant processes. Cryosphere 13(1):281296. https://doi.org/10.5194/tc-13-281-2019

Allison LC, Johnson HL, Marshall DP, Munday DR (2010) Where do winds drive the Antarctic Circumpolar Current? Geophys Res Lett. https://doi.org/10.1029/2010GL043355

Amores A, Jordà G, Arsouze T, Sommer JL (2018) Up to what extent can we characterize ocean eddies using present-day gridded altimetric products? J Geophys Res Oceans 123(10):7220-7236. https://doi.org/10.1029/2018JC014140

Amory C, Trouvilliez A, Gallée H, Favier V, Naaim-Bouvet F, Genthon C, Agosta C, Piard L, Bellot H (2015) Comparison between observed and simulated aeolian snow mass fluxes in Adélie Land, East Antarctica. Cryosphere 9:1373-1383

Andreas EL, Decosmo J (2002) The signature of sea spray in the Hexos turbulent heat flux data. Boundary-Layer Meteorol 103(2):303-333. https://doi.org/10.1023/A:1014564513650

Bailey DA, Lynch AH (2000) Development of an Antarctic regional climate system model. Part I: sea ice and large-scale circulation. J Clim 13(8):1337-1350

Ballarotta M, Ubelmann C, Pujol MI, Taburet G, Fournier F, Legeais JF, Faugere Y, Delepoulle A, Chelton D, Dibarboure G, Picot N (2019) On the resolutions of ocean altimetry maps. Ocean Sci. https://doi.org/10.5194/os-2018-156

Bintanja R, Van Oldenborgh G, Katsman C (2015) The effect of increased fresh water from Antarctic ice shelves on future trends in Antarctic sea ice. Ann Glaciol 56(69):120-126

Bougeault P, Lacarrere P (1989) Parameterization of orographyinduced turbulence in a Mesobeta-scale model. Mon Weather Rev 117(8):1872-1890

Boutin G, Ardhuin F, Dumont D, Sévigny C, Girard-Ardhuin F, Accensi M (2018) Floe size effect on wave-ice interactions: possible effects, implementation in wave model, and evaluation. J Geophys Res Oceans 123(7):4779-4805

Bromwich DH, Cassano JJ, Klein T, Heinemann G, Hines KM, Steffen K, Box JE (2001) Mesoscale modeling of katabatic winds over Greenland with the Polar MM5. Mon Weather Rev 129(9):2290-2309

Brun E, David P, Sudul M, Brunot G (1992) A numerical model to simulate snow-cover stratigraphy for operational avalanche forecasting. J Glaciol 38(128):13-22
Carrère L, Lyard F, Cancet M, Guillot A, Roblou L (2012) A new global tidal model taking taking advantage of nearly 20 years of altimetry. In: Proceedings of meeting 20 years of altimetry

Cassano JJ, Box JE, Bromwich DH, Li L, Steffen K (2001) Evaluation of polar MM5 simulations of Greenland's atmospheric circulation. J Geophys Res Atmos 106(D24):33867-33889. https:// doi.org/10.1029/2001JD900044

Cassianides A, Lique C, Korosov A (2021) Ocean eddy signature on SAR-derived sea ice drift and vorticity. Geophys Res Lett 48(6):e2020GL092066. https://doi.org/10.1029/2020GL092066

Chanut J, Barnier B, Large W, Debreu L, Penduff T, Molines JM, Mathiot P (2008) Mesoscale eddies in the Labrador sea and their contribution to convection and restratification. J Phys Oceanogr 38(8):1617-1643. https://doi.org/10.1175/2008JPO3485.1

Chelton D (2013) Mesoscale eddy effects. Nat Geosci 6(8):594-595. https://doi.org/10.1038/ngeo1906

Chelton DB, Xie SP (2010) Coupled ocean-atmosphere interaction at oceanic mesoscales. Oceanography 23(4):52-69

Chelton DB, deSzoeke RA, Schlax MG, Naggar KE, Siwertz N (1998) Geographical variability of the first baroclinic Rossby radius of deformation. J Phys Oceanogr 28(3):433-460

Chelton DB, Schlax MG, Samelson RM (2007) Summertime coupling between sea surface temperature and wind stress in the California Current System. J Phys Oceanogr 37(3):495-517

Craig A, Valcke S, Coquart L (2017) Development and performance of a new version of the OASIS coupler, OASIS3-MCT_3.0. Geosci Model Dev 10(9):3297-3308. https://doi.org/10.5194/ gmd-10-3297-2017

De Lavergne C, Palter JB, Galbraith ED, Bernardello R, Marinov I (2014) Cessation of deep convection in the open Southern Ocean under anthropogenic climate change. Nat Clim Change 4(4):278

De Ridder K, Gallée H (1998) Land surface-induced regional climate change in southern Israel. J Appl Meteorol 37(11):1470-1485

Donat-Magnin M, Jourdain NC, Gallée H, Amory C, Kittel C, Fettweis X, Wille JD, Favier V, Drira A, Agosta C (2020) Interannual variability of summer surface mass balance and surface melting in the Amundsen sector, West Antarctica. Cryosphere 14:229-249

Donlon CJ, Martin M, Stark J, Roberts-Jones J, Fiedler E, Wimmer W (2012) The operational sea surface temperature and sea ice analysis (OSTIA) system. Remote Sens Environ 116:140-158

Du Plessis M, Swart S, Ansorge IJ, Mahadevan A, Thompson AF (2019) Southern ocean seasonal restratification delayed by submesoscale wind-front interactions. J Phys Oceanogr 49(4):1035-1053

Duynkerke PG (1988) Application of the E- $\epsilon$ turbulence closure model to the neutral and stable atmospheric boundary layer. J Atmos Sci 45(5):865-880

Faghmous JH, Frenger I, Yao Y, Warmka R, Lindell A, Kumar V (2015) A daily global mesoscale ocean eddy dataset from satellite altimetry. Sci Data. https://doi.org/10.1038/sdata.2015.28

Ferrari R, Wunsch C (2010) The distribution of eddy kinetic and potential energies in the global ocean. Tellus A Dyn Meteorol Oceanogr 62(2):92-108

Foussard A, Lapeyre G, Plougonven R (2019) Storm track response to oceanic eddies in idealized atmospheric simulations. J Clim 32(2):445-463

Frenger I, Gruber N, Knutti R, Münnich M (2013) Imprint of Southern Ocean eddies on winds, clouds and rainfall. Nat Geosci 6(8):608-612

Frenger I, Münnich M, Gruber N, Knutti R (2015) Southern Ocean eddy phenomenology. J Geophys Res Oceans 120(11):7413-7449. https://doi.org/10.1002/2015JC011047

Gallée H, Schayes G (1994) Development of a three-dimensional Meso- $\gamma$ primitive equation model: katabatic winds simulation in the area of Terra Nova Bay, Antarctica. Mon Weather Rev 122(4):671-685 
Garcia D (2010) Robust smoothing of gridded data in one and higher dimensions with missing values. Comput Stat Data Anal 54(4):1167-1178. https://doi.org/10.1016/j.csda.2009.09.020

Gaspar P, Grégoris Y, Lefevre JM (1990) A simple eddy kinetic energy model for simulations of the oceanic vertical mixing: tests at station Papa and long-term upper ocean study site. J Geophys Res Oceans 95(C9):16179-16193

Gaube P, Chelton DB, Samelson RM, Schlax MG, O’Neill LW (2015) Satellite observations of mesoscale eddy-induced Ekman pumping. J Phys Oceanogr 45(1):104-132

Gryschka M, Drüe C, Etling D, Raasch S (2008) On the influence of sea-ice inhomogeneities onto roll convection in cold-air outbreaks. Geophys Res Lett. https://doi.org/10.1029/2008GL035845

Gupta M, Marshall J, Song H, Campin J, Meneghello G (2020) Sea-ice melt driven by ice-ocean stresses on the mesoscale. J Geophys Res Oceans. https://doi.org/10.1029/2020JC016404

Hallberg R (2013) Using a resolution function to regulate parameterizations of oceanic mesoscale eddy effects. Ocean Model 72:92-103

Haller G (2016) Dynamic rotation and stretch tensors from a dynamic polar decomposition. J Mech Phys Solids 86:70-93. https://doi. org/10.1016/j.jmps.2015.10.002

Hausmann U, McGillicuddy DJ Jr, Marshall J (2017) Observed mesoscale eddy signatures in Southern Ocean surface mixed-layer depth. J Geophys Res Oceans 122(1):617-635

Hersbach H, Bell B, Berrisford P, Hirahara S, Horányi A, MuñozSabater J, Nicolas J, Peubey C, Radu R, Schepers D et al (2020) The ERA5 global reanalysis. Q J R Meteorol Soc 146(730):1999-2049

Hogg AM (2010) An Antarctic circumpolar current driven by surface buoyancy forcing. Geophys Res Lett. https://doi.org/10.1029/ 2010GL044777

Horvat C, Tziperman E, Campin JM (2016) Interaction of sea ice floe size, ocean eddies, and sea ice melting. Geophys Res Lett 43(15):8083-8090

Huot PV, Fichefet T, Jourdain NC, Mathiot P, Rousset C, Kittel C, Fettweis $X$ (2021) Influence of ocean tides and ice shelves on oceanice interactions and dense shelf water formation in the D'Urville Sea, Antarctica. Ocean Model 162:101794. https://doi.org/10. 1016/j.ocemod.2021.101794

Huot PV, Kittel C, Fichefet T, Jourdain NC, Sterlin J, Fettweis X (2021) Effects of the atmospheric forcing resolution on simulated sea ice and polynyas off Adélie Land, East Antarctica. Ocean Model 168:101901. https://doi.org/10.1016/j.ocemod.2021.101901

Jeong H, Asay-Davis XS, Turner AK, Comeau DS, Price SF, Abernathey RP, Veneziani M, Petersen MR, Hoffman MJ, Mazloff MR et al (2020) Impacts of ice-shelf melting on Water-mass transformation in the Southern Ocean from E3SM simulations. J Clim 33(13):5787-5807

Jourdain NC, Mathiot P, Gallée H, Barnier B (2011) Influence of coupling on atmosphere, sea ice and ocean regional models in the Ross Sea sector, Antarctica. Clim Dyn 36(7-8):1523-1543

Jourdain NC, Molines JM, Le Sommer J, Mathiot P, Chanut J, de Lavergne C, Madec G (2019) Simulating or prescribing the influence of tides on the Amundsen Sea ice shelves. Ocean Model 133:44-55

Kittel C, Amory C, Agosta C, Delhasse A, Doutreloup S, Huot PV, Wyard C, Fichefet T, Fettweis X (2018) Sensitivity of the current Antarctic surface mass balance to sea surface conditions using MAR. Cryosphere 12:3827-3839

Kittel C, Amory C, Agosta C, Jourdain NC, Hofer S, Delhasse A, Doutreloup S, Huot PV, Lang C, Fichefet T (2021) Diverging future surface mass balance between the Antarctic ice shelves and grounded ice sheet. Cryosphere 15(3):1215-1236

Kozlov IE, Artamonova AV, Manucharyan GE, Kubryakov AA (2019) Eddies in the Western Arctic Ocean from spaceborne SAR observations over open ocean and marginal ice zones. J Geophys Res
Oceans 124(9):6601-6616. https://doi.org/10.1029/2019JC0151 13

LaCasce JH, Groeskamp S (2020) Baroclinic modes over rough bathymetry and the surface deformation radius. J Phys Oceanogr 50(10):2835-2847. https://doi.org/10.1175/JPO-D-20-0055.1

Large WG, Yeager SG (2004) Diurnal to decadal global forcing for ocean and sea-ice models: the data sets and flux climatologies. NCAR Tech Note

Lavergne T, Sørensen AM, Kern S, Tonboe R, Notz D, Aaboe S, Bell L, Dybkjæer G, Eastwood S, Gabarro C et al (2019) Version 2 of the EUMETSAT OSI SAF and ESA CCI sea-ice concentration climate data records. Cryosphere 13(1):49-78

Lazar A, Madec G, Delecluse P (1999) The deep interior downwelling, the veronis effect, and mesoscale tracer transport parameterizations in an OGCM. J Phys Oceanogr 29(11):2945-2961

Le Bars D, Viebahn JP, Dijkstra HA (2016) A Southern Ocean mode of multidecadal variability. Geophys Res Lett 43(5):2102-2110. https://doi.org/10.1002/2016GL068177

Locarnini R, Mishonov A, Baranova O, Boyer T, Zweng M, Garcia H, Reagan J, Seidov D, Weathers K, Paver C, Smolyar I (2018) World Ocean Atlas 2018. Temperature. NOAA Atlas NESDIS 81 Edition, A. Mishonov, vol 1

Lüpkes C, Gryanik VM, Hartmann J, Andreas EL (2012) A parametrization, based on sea ice morphology, of the neutral atmospheric drag coefficients for weather prediction and climate models. J Geophys Res Atmos. https://doi.org/10.1029/2012j d017630

Madec G (2016) NEMO ocean engine. Note du Pôle de modélisation, Institut Pierre-Simon Laplace (IPSL), France, No 27, ISSN No 1288-1619

Manucharyan GE, Thompson AF (2017) Submesoscale Sea IceOcean Interactions in marginal ice zones. J Geophys Res Oceans 122(12):9455-9475. https://doi.org/10.1002/2017jc012895

Maraldi C, Chanut J, Levier B, Ayoub N, De Mey P, Reffray G, Lyard F, Cailleau S, Drévillon M, Fanjul E et al (2013) NEMO on the shelf: assessment of the Iberia-Biscay-Ireland configuration. Ocean Sci 9(4):745-71

Marbaix P, Gallée H, Brasseur O, Ypersele JPV (2003) Lateral boundary conditions in regional climate models: a detailed study of the relaxation procedure. Mon Weather Rev 131(3):461-479

Marshall J, Radko T (2003) Residual-mean solutions for the Antarctic circumpolar current and its associated overturning circulation. J Phys Oceanogr 33(11):2341-2354

Marshall J, Speer K (2012) Closure of the meridional overturning circulation through Southern Ocean upwelling. Nat Geosci 5(3):171180. https://doi.org/10.1038/ngeo1391

Martinson DG (2012) Antarctic circumpolar current's role in the Antarctic ice system: an overview. Palaeogeogr Palaeoclimatol Palaeoecol 335-336:71-74. https://doi.org/10.1016/j.palaeo.2011. 04.007

McWilliams JC (2008) The nature and consequences of oceanic eddies. Ocean Model Eddying Regime 177:5-15

McWilliams JC (2016) Submesoscale currents in the ocean. Proc R Soc A Math Phys Eng Sci 472(2189):20160117. https://doi.org/ 10.1098/rspa.2016.0117

Meneghello G, Marshall J, Lique C, Isachsen PE, Doddridge E, Campin JM, Regan H, Talandier C (2020) Genesis and decay of mesoscale baroclinic eddies in the seasonally ice-covered interior arctic ocean. J Phys Oceanogr 51(1):115-129. https://doi.org/10. 1175/JPO-D-20-0054.1

Moreau S, Penna AD, Llort J, Patel R, Langlais C, Boyd PW, Matear RJ, Phillips HE, Trull TW, Tilbrook B, Lenton A, Strutton PG (2017) Eddy-induced carbon transport across the Antarctic circumpolar current. Glob Biogeochem Cycles 31(9):1368-1386. https://doi.org/10.1002/2017GB005669 
O'Neill LW, Chelton DB, Esbensen SK, Wentz FJ (2005) High-resolution satellite measurements of the atmospheric boundary layer response to SST variations along the agulhas return current. J Clim 18(14):2706-2723. https://doi.org/10.1175/JCLI3415.1

Orsi A, Johnson G, Bullister J (1999) Circulation, mixing, and production of Antarctic bottom water. Prog Oceanogr 43(1):55-109

Renault L, Molemaker MJ, McWilliams JC, Shchepetkin AF, Lemarié F, Chelton D, Illig S, Hall A (2016) Modulation of wind work by oceanic current interaction with the atmosphere. J Phys Oceanogr 46(6):1685-1704. https://doi.org/10.1175/jpo-d-15-0232.1

Renault L, McWilliams JC, Masson S (2017) Satellite observations of imprint of oceanic current on wind stress by air-sea coupling. Sci Rep 7(1):17747. https://doi.org/10.1038/s41598-017-17939-1

Renault L, Masson S, Oerder V, Jullien S, Colas F (2019) Disentangling the mesoscale ocean-atmosphere interactions. J Geophys Res Oceans 124(3):2164-2178. https://doi.org/10.1029/2018J C014628

Rignot E, Mouginot J, Scheuchl B, van den Broeke M, van Wessem MJ, Morlighem M (2019) Four decades of Antarctic Ice Sheet mass balance from 1979-2017. Proc Natl Acad Sci 116(4):1095-1103. https://doi.org/10.1073/pnas.1812883116

Rousset C, Vancoppenolle M, Madec G, Fichefet T, Flavoni S, Barthélemy A, Benshila R, Chanut J, Levy C, Masson S, Vivier F (2015) The Louvain-La-Neuve sea ice model LIM3.6: global and regional capabilities. Geosci Model Dev 8(10):2991-3005. https:// doi.org/10.5194/gmd-8-2991-2015

Shine KP, Henderson-Sellers A (1985) The sensitivity of a thermodynamic sea ice model to changes in surface albedo parameterization. J Geophys Res Atmos 90(D1):2243-2250. https://doi.org/ 10.1029/JD090iD01p02243

Small RJ, deSzoeke SP, Xie SP, O'Neill L, Seo H, Song Q, Cornillon P, Spall M, Minobe S (2008) Air-sea interaction over ocean fronts and eddies. Dyn Atmos Oceans 45(3):274-319. https://doi.org/10. 1016/j.dynatmoce.2008.01.001

Small RJ, Msadek R, Kwon YO, Booth JF, Zarzycki C (2019) Atmosphere surface storm track response to resolved ocean mesoscale in two sets of global climate model experiments. Clim Dyn 52(3):2067-2089

Sokolov S, Rintoul SR (2009) Circumpolar structure and distribution of the Antarctic circumpolar current fronts: 1 mean circumpolar paths. J Geophys Res Oceans 114(C11):1

Song Q, Chelton DB, Esbensen SK, Thum N, O'Neill LW (2009) Coupling between Sea surface temperature and low-level winds in mesoscale numerical models. J Clim 22(1):146-164. https://doi. org/10.1175/2008JCLI2488.1

Song H, Marshall J, McGillicuddy DJ, Seo H (2020) Impact of currentwind interaction on vertical processes in the Southern Ocean. J Geophys Res Oceans 125(4):e2020JC016046. https://doi.org/10. 1029/2020JC016046

Soufflet Y, Marchesiello P, Lemarié F, Jouanno J, Capet X, Debreu L, Benshila R (2016) On effective resolution in ocean models. Ocean Model 98:36-50. https://doi.org/10.1016/j.ocemod.2015.12.004

Souza JMAC, de Boyer MC, Le Traon PY (2011) Comparison between three implementations of automatic identification algorithms for the quantification and characterization of mesoscale eddies in the South Atlantic Ocean. Ocean Sci 7(3):317-334. https://doi.org/ 10.5194/os-7-317-2011

Stewart AL, Klocker A, Menemenlis D (2018) Circum-Antarctic shoreward heat transport derived from an eddy-and tide-resolving simulation. Geophys Res Lett 45(2):834-845

Tarshish N, Abernathey R, Zhang C, Dufour CO, Frenger I, Griffies SM (2018) Identifying Lagrangian coherent vortices in a mesoscale ocean model. Ocean Model 130:15-28. https://doi.org/10.1016/j. ocemod.2018.07.001

Van Achter G, Fichefet T, Goosse H, Pelletier C, Huot PV, Sterlin J, Fraser AD, Parter-Smith R, Lemieux JF, Haubner K (2021) Modelling landfast sea ice and its influence on ocean-ice interactions in the area of the Totten Glacier, East Antarctica. Ocean Model 168:101901

van Lipzig NP, van Meijgaard E, Oerlemans J (2002) Temperature sensitivity of the Antarctic surface mass balance in a regional atmospheric climate model. J Clim 15(19):2758-2774

Vancoppenolle M, Fichefet T, Goosse H, Bouillon S, Madec G, Maqueda MAM (2009) Simulating the mass balance and salinity of Arctic and Antarctic sea ice. 1. Model description and validation. Ocean Model 27(1-2):33-53. https://doi.org/10.1016/j. ocemod.2008.10.005

Villas Bôas AB, Sato OT, Chaigneau A, Castelão GP (2015) The signature of mesoscale eddies on the air-sea turbulent heat fluxes in the South Atlantic Ocean. Geophys Res Lett 42(6):1856-1862

Walin G (1982) On the relation between sea-surface heat flow and thermal circulation in the ocean. Tellus 34(2):187-195

Wang Y (2001) An explicit simulation of tropical cyclones with a triply nested movable mesh primitive equation model: TCM3. Part I: Model description and control experiment. Mon Weather Rev 129(6):1370-1394

Wang G, Garcia D, Liu Y, de Jeu R, Johannes Dolman A (2012) A three-dimensional gap filling method for large geophysical datasets: application to global satellite soil moisture observations. Environ Model Softw 30:139-142. https://doi.org/10.1016/j.envso ft.2011.10.015

Williams S, Petersen M, Bremer PT, Hecht M, Pascucci V, Ahrens J, Hlawitschka M, Hamann B (2011) Adaptive extraction and quantification of geophysical vortices. IEEE Trans Vis Comput Graph 17(12):2088-2095. https://doi.org/10.1109/TVCG.2011.162

Zweng M, Reagan J, Seidov D, Boyer T, Locarnini R, Garcia H, Mishonov A, Baranova O, Weathers K, Paver C, Smolyar I (2018) World Ocean Atlas 2018. In: Mishonov A (eds) vol 2. NOAA Atlas NESDIS 82, Salinity

Publisher's Note Springer Nature remains neutral with regard to jurisdictional claims in published maps and institutional affiliations. 